\title{
Inhibitory associations between neutral stimuli: A comparative approach
}

\author{
A. A. ARTIGAS and V. D. CHAMIZO \\ Universitat de Barcelona, Barcelona, Spain \\ and \\ J. M. PERIS \\ Universitat Politècnica de Catalunya, Barcelona, Spain
}

\begin{abstract}
In Experiments 1A, 1B, and 1C, nonhuman subjects, rats, received long alternated exposures to two compound flavors, $\mathrm{AX}$ and $\mathrm{BX}$, that shared one flavor in common, $\mathrm{X}$. Following this, conditioning of an aversion to A was sufficient to establish B as a conditioned inhibitor of the aversive unconditioned stimulus, passing both summation and retardation tests. Two additional experiments (Experiments 2 and 3) expanded the generality of these results to humans, using similar designs but an auditory discrimination learning task. A set of notes sequentially presented served as cues and fictitious composers served as outcomes. Both summation and retardation effects were found (Experiments 2 and 3, respectively). Experiment 4 then sought to clarify the mechanism underlying these effects. The results are discussed within several theoretical frameworks, most centrally the McLaren, Kaye, and Mackintosh (1989) theory of perceptual learning.
\end{abstract}

Espinet, Iraola, Bennett, and Mackintosh (1995) demonstrated that long alternated exposures to two compound flavors, $\mathrm{AX}$ and $\mathrm{BX}$, containing a common element, $\mathrm{X}$, followed by the conditioning of an aversion to A, is sufficient to establish $\mathrm{B}$ as a conditioned inhibitor of the unconditioned stimulus (US) used to reinforce aversive conditioning. In their Experiments 1 and 3, B was slow to acquire aversive properties when paired with the US itself (a retardation test for inhibition); in their Experiments 2 and 4, B reduced the aversion conditioned to another conditioned stimulus (CS; a summation test for inhibition). Exposure to A and B in the absence of the common element, $\mathrm{X}$, was not sufficient to produce the retardation effect (their Experiment 3). And when AX and BX exposures were short, it did not produce the summation effect (their Experiment 4). Alternative explanations (latent inhibition, external inhibition, and generalization decrement) were considered and discounted. The Espinet et al. results show that long alternated preexposures to two neutral stimuli that share a common element are sufficient

This research was supported by Grant PB97-0965 from the Spanish Ministerio de Educación y Ciencia. The human equipment was built in the Departament d'Engineria de Sistemes, Automàtica i Informàtica Industrial of the Universitat Politécnica de Catalunya. We are very grateful to Antoni Besses for elaborating the score used in the human experiments and for his musical advice in collaboration with Montserrat Vall-lloveras. We are also grateful to Helena Matute for her many helpful comments on an earlier version of this manuscript and to Ralph R. Miller for excellent comments and for endless patience with the final manuscript in order to improve our English writing. Correspondence should be addressed to V. D. Chamizo, Universitat de Barcelona, Departament de Psicologia Bàsica, Passeig de la Vall d'Hebron, 171, 08035-Barcelona, Spain (e-mail: vdchamizo@psi.ub.es). to create an inhibitory association between them. In order to measure this silent inhibitory association, subsequent first-order conditioning is necessary, as is done to demonstrate that two neutral stimuli are excitatory associated. For example, Rizley and Rescorla (1972) demonstrated that after a tone has been paired with a light, and the light then paired with a shock, rats are frightened by the presentation of the tone, even though the tone itself has never been presented with the shock.

The results of Espinet et al. (1995) seem to contradict what would be expected according to the theory of mediated generalization or acquired equivalence (e.g., Hall, 1991): If two stimuli, A and B, are both associated with a third common stimulus, $X$, this should enhance generalization between them. But, in practice, prolonged preexposure to one or two compound stimuli that share some common elements tends to facilitate the subsequent discrimination between them (i.e., a perceptual learning effect is observed) rather than increase generalization between them (for empirical evidence on spatial discrimination tasks in a maze, see Chamizo \& Mackintosh, 1989, Rodrigo, Chamizo, McLaren, \& Mackintosh, 1994, and Sansa, Chamizo, \& Mackintosh, 1996; in a Morris pool, see Prados, Chamizo, \& Mackintosh, 1999; with a taste aversion procedure, see Artigas \& Chamizo, 1994, Bennett, Wills, Wells, \& Mackintosh, 1994, Mackintosh, Kaye, \& Bennett, 1991, and Symonds \& Hall, 1995). In the Artigas and Chamizo study (1994), rats were injected with lithium chloride after drinking a solution with a distinctive flavor. Then, both the aversion to the conditioned flavor and the generalization to a new and nonconditioned flavor were measured. Rats preexposed and conditioned to either a single flavor, A or B, or to a compound one, AX 
or BX, showed less aversion to the preexposed and conditioned flavor than did nonpreexposed rats (i.e., latent inhibition effect was found in both cases). Most important, preexposure to the compound flavor, either AX or BX, facilitated the subsequent discrimination between these two compounds (i.e., a perceptual learning effect was obtained), and this facilitation did not occur when simple flavors were used. The explanation favored by the authors referred to the latent inhibition acquired by $\mathrm{X}$ during preexposure: Only when the compound stimuli were used, $\mathrm{AX}$ and BX, the associability of the element shared by the two, $\mathrm{X}$, was reduced during preexposure, thus allowing a subsequent good discrimination between both compounds (McLaren, Kaye, \& Mackintosh, 1989).

Espinet et al. (1995) explained their results within the McLaren et al. (1989) theory of perceptual learning (see Appendix A for a brief explanation of the McLaren et al., 1989 , model), although they noticed that a small modification of the model was necessary. According to the original McLaren et al. model, alternated preexposures to AX and $\mathrm{BX}$ will produce strong within-compound associations both between A and X and between B and X (Rescorla \& Cunningham, 1978). These within-compound associations will increase generalization between $\mathrm{AX}$ and $\mathrm{BX}$ because of the presence of $\mathrm{X}$ in both compound stimuli (i.e., due to mediated generalization or acquired equivalence). But eventually, in the presence of $\mathrm{AX}, \mathrm{X}$ will activate a representation of $\mathrm{B}$, thus allowing the formation of an inhibitory association from $\mathrm{A}$ to $\mathrm{B}$; in the presence of $\mathrm{BX}$, $\mathrm{X}$ will activate a representation of $\mathrm{A}$, thus allowing the formation of an inhibitory association from B to A. Such mutual inhibitory associations between $\mathrm{A}$ and $\mathrm{B}$, the unique elements of the compound stimuli, will counteract the previous increased generalization between $A X$ and BX. Although inhibition (negative weights) was allowed, negative activation of units was not permitted.

The modification of the model proposed by Espinet et al. (1995) consisted in allowing that the net activations of the stimuli to vary between -1 and +1 (instead of between 0 and +1 , as it is recommended in the model), so as to permit negative activations. And when this is the case, it is possible that $\mathrm{B}$, activated through $\mathrm{A}$ in the conditioning phase, becomes a conditioned inhibitor of the aversive US (this result is obtained when applying the equation for changing the weight between $\mathrm{B}$ and the aversive US in the $\mathrm{A} \rightarrow \mathrm{US}$ conditioning trial; see Appendix A for details of the McLaren et al., 1989, model), thus explaining the summation and retardation effects they found. Therefore, this explanation allows that a negatively activated stimulus (that is, B in the conditioning phase) can change its associative strength.

Recently, Bennett, Scahill, Griffiths, and Mackintosh (1999) have proposed a second and simpler explanation for the Espinet et al. (1995) results, also within the McLaren et al. (1989) model (although allowing that the activation of the stimuli vary between -1 and +1 , as suggested by Mclaren in the Espinet et al. paper). It refers to an explanation in terms of performance. Bennett et al. (1999) have demonstrated that a negatively activated stimulus (i.e., $\mathrm{B}$ in the conditioning phase) cannot change its associative strength. According to these authors, due to the mutual inhibitory associations formed between A and B during preexposure, in the test phase (be it either a retardation or a summation test for inhibition), B will negatively activate both the unique element A and the US now associated with it, with the consequence of a negative impact on the subject's behavior. These authors contrasted the two mechanisms by establishing unidirectional backward inhibitory associations during the preexposure to two compound flavors, AX and BX. Specifically, by preexposing the AX pair reliably preceded by the $\mathrm{BX}$ pair in a group of animals (thus allowing the formation of a backward inhibitory association from $\mathrm{A}$ to $\mathrm{B}$, an $\mathrm{A} \dashv \mathrm{B}$ association, and not vice versa), and the BX pair reliably preceded by the AX pair in a second group of animals (thus allowing the formation of a backward inhibitory association from $\mathrm{B}$ to $\mathrm{A}, \mathrm{a} \mathrm{B} \dashv \mathrm{A}$ association, and not vice versa). In the first case, an inhibitory association from $A$ to $B$ should drive $\mathrm{B}$ negative during conditioning but have no effect when B is presented on test. Conversely, in the second case, an inhibitory association from B to A should be without effect during conditioning but should affect preferences on test. Their results favored the second mechanism (Bennett et al., 1999), thus suggesting that negatively activated stimuli cannot change their associative strength.

There is additional evidence that the preexposure schedule is critical in generating a perceptual learning effect when preexposing two compound solutions, AX and BX, which contain a common element, X. Symonds and Hall (1995; see also Bennett \& Mackintosh, 1999) have demonstrated that alternate preexposures to two compound flavors, such as $\mathrm{AX}$ and $\mathrm{BX}$, are more effective in reducing generalization between them than are preexposure treatments in which the two flavors are presented in separate blocks of trials (for a similar finding, see Honey, Bateson, $\&$ Horn, 1994). Symonds and Hall suggested that the opportunity for stimulus comparison offered by the alternating schedule could be important in a process of perceptual learning that is responsible for the reduced generalization. This explanation was suggested to substitute for the mechanism of the formation of the mutually inhibitory associations between A and B proposed by McLaren et al. (1989). But in the study by Bennett and Mackintosh (1999), there was the suggestion that the opportunity to compare stimuli sharing a common element, such as AX and BX, can facilitate discrimination between them because their distinctive features, $\mathrm{A}$ and $\mathrm{B}$, are presumably attended to at the expense of their common feature, $X$. Thus, a reduction in the interval between alternating presentations of $\mathrm{AX}$ and $\mathrm{BX}$ should provide greater opportunity for comparison and, consequently, better discrimination. Bennett and Mackintosh's results demonstrated that when the interval between exposure to the compound stimuli, $\mathrm{AX}$ and $\mathrm{BX}$, was reduced to $0 \mathrm{sec}$, the alternating schedule increased generalization between $\mathrm{AX}$ and $\mathrm{BX}$, thereby suggesting that the reason why 
alternating preexposure is more effective than blocked preexposure in reducing generalization from $\mathrm{AX}$ to $\mathrm{BX}$ is that such alternation allows the formation of inhibitory associations between $\mathrm{A}$ and $\mathrm{B}$. (For an additional interpretation concerning why a large amount of training is critical in generating conditioned inhibition, see Yin, Barnet, \& Miller, 1994.)

The experiments we present here had several purposes. First, we wanted to determine whether we could replicate the Espinet et al. (1995) results with nonhuman subjects, rats, that received spaced alternated preexposures to two compound flavors, AX and BX, containing a common element, $X$, followed by the conditioning of an aversion to A: Would this treatment be sufficient to establish $\mathrm{B}$ like a stimulus that performs as a conditioned inhibitor of the US, passing both summation and retardation tests for inhibition (Experiments 1A, 1B, and 1C)? Second, and most important, these experiments were intended to expand the generality of these results to humans using similar designs but an auditory discrimination learning task, in which a set of notes sequentially presented served as cues and fictitious composers served as outcomes (Experiments 2-4). There are very few behavioral preparations for studying Pavlovian conditioning with humans (but see and Arcediano, Ortega, \& Matute, 1996; Pineño, Ortega, \& Matute, 2000; and Shanks \& Dickinson, 1991). Human judgments of causality have been a frequent measure in recent years. In fact, human judgments of causality and animal conditioning studies are viewed as analogues by many authors (e.g., Skanks \& Dickinson, 1987; Wasserman, 1993; Young, 1995). But we believe that the use of a behavioral preparation provides a more appropriate measurement than does the use of verbal judgments. There are sufficient demonstrations that many undesired variables can influence verbal judgments. For example, Matute, Arcediano, and Miller (1996) have shown that small differences in the way the test questions or the names of the fictitious causes and effects in verbal causal preparations are phrased can substantially influence the results. Catena, Maldonado, and Cándido (1998) have recently demonstrated that how frequently the subjects are asked to give a judgment is also an important variable. They found different results when asking for trial-by-trial judgments in comparison with the judgments they obtained once the subjects were presented with all the information. It has been suggested that different and independent learning systems could be responsible for the verbal judgments on one hand and for the behavioral data on the other hand (Shanks \& St. John, 1994). For these reasons, in the present human experiments, we used a new behavioral preparation for human subjects. The question of interest was whether spaced alternated exposures to two compound "melodies," XA and XB, containing a melody in common, $\mathrm{X}$, followed by the conditioning of one melody, A, to a fictitious composer is sufficient to establish melody B as a possible conditioned inhibitor of the specific composer associated with melody A, thereby passing both summation and retardation tests for inhibi- tion (Experiments 2 and 3). In addition, a complementary experiment, Experiment 4, was designed to try to clarify which of the two proposed explanations within the framework of the McLaren et al. (1989) model is responsible for B performing as a conditioned inhibitor of the composer associated with A. Other theories are also considered.

\section{EXPERIMENT 1}

In Espinet et al.'s (1995) Experiment 1, three groups of rats were preexposed to $\mathrm{AX}$ and $\mathrm{BX}$ on alternate days. Each compound solution was presented $24 \mathrm{~h}$ apart. Then two groups received an injection of lithium chloride, one of them after drinking A (Group $\mathrm{A}+$ ) and the second group after drinking $\mathrm{X}$ (Group $\mathrm{X}+$ ); a third, control group received an injection of physiological saline after drinking A (Group A). Following this, all rats were trained on an aversion to B; consumption of B was paired with a lithium chloride injection (a retardation test). Group X+ conditioned an aversion to $\mathrm{B}$ more rapidly than did Group A, the control group, and Group A+ conditioned the aversion to B more slowly than did Group A. Their interpretation was that, in Group A+, B became a conditioned inhibitor of the US. In their second experiment, Espinet et al. wanted to see whether, in Group A+, B would pass a summation test of conditioned inhibition. Their experiment had two groups, A+ and A. All rats were preexposed to $A X$ and $B X$. Then, after drinking $A$, rats in Group A+ received an injection of lithium chloride, and rats in Group A received an injection of saline. In the next phase of the experiment, all animals were given a new fluid, Q, and its consumption was paired with a lithium injection. In the final phase of the experiment, rats were given a compound solution to drink, $\mathrm{BQ}$, and the aversion to this solution was measured (a summation test). They found that Group A+ showed less aversion to the compound solution, BQ, than did Group A. As in their first experiment, their interpretation was that, in Group A+, B became a conditioned inhibitor of the US.

The present Experiments 1A and 1B were designed to replicate this summation effect. Experiment $1 \mathrm{~A}$ had three groups: Group A+, Group A, and Group Au+. Following alternated exposure to $\mathrm{AX}$ and $\mathrm{BX}$, rats in Group A+ received an injection of lithium chloride after drinking A, whereas rats in Group A received the same injection but $24 \mathrm{~h}$ before drinking A. The third group, Group $\mathrm{Au}+$, was added to determine whether exposure to $\mathrm{A}$ and $\mathrm{B}$ in the absence of the common element, $X$, would be sufficient to produce a (negative) summation effect. Then all animals were given a new fluid to drink, Q, and its consumption was paired with a lithium injection. In the final phase of the experiment, rats were given a compound solution to drink, BQ, and the aversion to this solution was measured (a summation test). Experiment 1B had only two groups, Group B+ and Group B. This experiment was designed to compensate for the lack of fluids counterbalancing in the previous experiment. It was identical to Experiment $1 \mathrm{~A}$ except that, in the conditioning phase, all rats were allowed 
Table 1

Design of Experiment 1

\begin{tabular}{llccc}
\hline \multicolumn{1}{c}{ Group } & Preexposure* & Cond A & Cond Q & Summation Test \\
\hline Experiment 1A & & & & \\
A+ & AX, BX & A+ & Q+ & BQ \\
A & AX, BX & $+\mathrm{A}$ & Q+ & BQ \\
Au+ & A, B & A+ & Q+ & BQ \\
Experiment 1B & & & & AQ \\
B+ & AX, BX & B+ & Q+ & AQ \\
B & AX, BX & $+\mathrm{B}$ & Q+ \\
Experiment 1C & & \multicolumn{2}{c}{ Retardation Test } \\
A+ & AX, BX & A+ & \multicolumn{2}{c}{ B+ } \\
A & AX, BX & $+\mathrm{A}$ & \multicolumn{2}{c}{ B+ } \\
\hline
\end{tabular}

A, acid; B, salt; X, saccharin; Q, quinine; +, LiCl (always 0.15 M). *Each solution (compound or single) was presented every day with $5 \mathrm{~h}$ difference.

to drink B, instead of $\mathrm{A}$, and that, in the final phase of the experiment, the compound solution to drink was AQ, instead of BQ as in Experiment 1A. Experiment 1C also had two groups, Group A+ and Group A. These groups were identical to the Groups A+ and A in Experiment $1 \mathrm{~A}$, except that the final phase of the experiment was a retardation test instead of a summation one.

\section{Experiment 1A}

\section{Method}

Subjects. The subjects were 22 naive Long-Evans rats, 12 males and 10 females, approximately 3 months old at the beginning of the experiment. They were divided into three groups, according to their sex and consumptions in a preliminary phase: Group A+ (4 males and 3 females), Group A (4 males and 3 females), and Group Au+ ( 4 males and 4 females). The rats were housed in pairs or in groups of 3 in standard cages of polycarbonate plastic $(50 \mathrm{~cm}$ long, $25 \mathrm{~cm}$ wide, and $20 \mathrm{~cm}$ high) in a room in which the light/dark was from 0900 to 2100 ; they were tested within the last third of the light cycle. They had ad-lib access to food but were on a water-deprivation schedule. Throughout the experiment, the subjects had access to water in the home cages for $15 \mathrm{~min}$, approximately $6 \mathrm{~h}$ after the end of the first experimental session. Therefore, they could drink three times a day during preexposure (twice during the preexposure sessions and once in the home cages) and only two times a day for the rest of the experiment.

Apparatus. The experimental cages were standard cages of hard plastic $(25 \times 25 \times 20 \mathrm{~cm})$, painted black, and situated in the same room as the home cages, but on an opposite wall. The different solutions were presented to the subjects through a graduated $25-\mathrm{ml}$ glass tube, which ended with a metal spout ( $3 \mathrm{~cm}$ long) inserted into each cage. The tube rested on the steel grid cover of the cage, forming an angle of approximately $45^{\circ}$ with the base of the cage, in such a way that the spout reached into the middle of the cage. It was secured so that it did not move when the rats were drinking. The different solutions were the following: citric acid, referred to as A $(0.3 \%)$; table salt, referred to as B $(0.5 \%)$; sodium saccharin, referred to as X $(0.03 \%)$; and quinine, referred as Q $(0.00005 \mathrm{M})$, always diluted with distilled water.

Procedure. The water-deprivation schedule lasted for 6 days. On Day 1, the rats had access to tap water in their home cages for $5 \mathrm{~h}$, and then the access time was reduced by $45 \mathrm{~min}$ each day, so that on Day 6, access time to water was $75 \mathrm{~min}$. Then, pretraining began. The rats had 3 days of water in the experimental cages, twice a day, with $5 \mathrm{~h}$ between sessions. At the end of pretraining, the subjects were assigned to the three groups. The next 10 days constituted the preexposure phase (see Table 1). The rats in Groups A+ and A had separated access to the two compound solutions, AX and BX; the rats in Group $\mathrm{Au}+$ had separated access to the single solutions, acid and salt. These solutions, compound or single, were each presented once on each day, with an interval of $5 \mathrm{~h}$ between them. The next 4 days constituted the conditioning phase. During this phase and also for the rest of the experiment, the rats had only one drinking session in the experimental cages instead of two. In this session, on the 1st and 3rd days of the conditioning phase, the rats in Group $\mathrm{A}+$ and $\mathrm{Au}+\mathrm{had}$ access to acid (A), and the rats in Group A had access to tap water; approximately 5-10 min after consumption, all rats received an intraperitoneal injection of $\mathrm{LiCl}(0.15 \mathrm{M}, 10 \mathrm{ml} / \mathrm{kg})$. On the 2nd and 4th days, the rats in Group $\mathrm{A}+$ and $\mathrm{Au}+$ had access to water, and the rats in Group A had access to the acid solution (A). The following day, all rats received acid (A) in order to evaluate the aversion for it. After 2 days of rest in which the rats had access to water in the experimental cages, all rats were conditioned to a new solution, quinine (Q) for 1 day. Then, after 1 day of rest in which the rats had access to water in the experimental cages, all rats had access to the quinine solution $(\mathrm{Q})$ in order to evaluate the aversion for it. The summation phase constituted the next and last day of the experiment. All rats had access to a compound solution formed by salt-quinine (BQ). All flavor presentations were $15 \mathrm{~min}$ in duration.

\section{Results and Discussion}

In the preexposure phase, during the last two presentations of the acid-saccharine compound (AX), Groups $\mathrm{A}+$ and $\mathrm{A}$ had mean consumptions of 3.9 and $3.8 \mathrm{ml}$, respectively, and the mean consumption in the last two presentations of acid in Group Au+ was $2.6 \mathrm{ml}(F \mathrm{~s}<1.5)$. In the last two presentations of the salt-saccharine compound (BX), Groups A+ and A had mean consumptions of 11.2 and $10.2 \mathrm{ml}$, respectively, and the mean consumption in the last two presentations of salt in Group Au+ was $7.6 \mathrm{ml}[F(2,19)=5.23, p<.05]$. Additional analysis showed that the salt-saccharine compound (BX) was consumed more than the salt solution (B). In the first conditioning phase, the mean consumptions of the acid solution (A) of the three groups, averaging the two presentations of this solution, were of $2.3 \mathrm{ml}$ for Group A+, $2.2 \mathrm{ml}$ for Group A, and $1.9 \mathrm{ml}$ for Group Au+ $(F<0.5)$. In the testto-A day, the consumptions of the acid solution (A) of the three groups were $0.7 \mathrm{ml}$ for Group A+, $2.1 \mathrm{ml}$ for Group A, and $0.8 \mathrm{ml}$ for Group Au+ $[F(2,19)=4.85, p<$ .05]. Newman-Keuls pairwise comparisons showed that Groups $\mathrm{A}+$ and $\mathrm{Au}+$ did not differ and that both did differ from Group A. In the second conditioning phase, the mean consumptions of the quinine solution $(\mathrm{Q})$ of the three groups were $1.5 \mathrm{ml}$. for Group A+, $2.0 \mathrm{ml}$ for Group A, and $3.3 \mathrm{ml}$ for Group $\mathrm{Au}+(F<3.0)$.

Figure 1 shows the mean consumption of the quinine solution (Q) in the test day and of the salt-quinine solution (BQ) in the summation test day. On the test-to-Q day, the intake of the three groups did not differ $(F<0.5)$, on the summation test day, the groups did differ $[F(2,19)=$ $5.82, p<.05]$. Newman-Keuls pairwise comparisons showed that Group A+ differed from Groups A and Au+, which did not differ between themselves. In conclusion, these results show a clear summation effect: In Group A+, the presence of B reduced the suppression of intake of $Q$ induced by pairing $\mathrm{Q}$ with $\mathrm{LiCl}$, whereas in Group A, it 


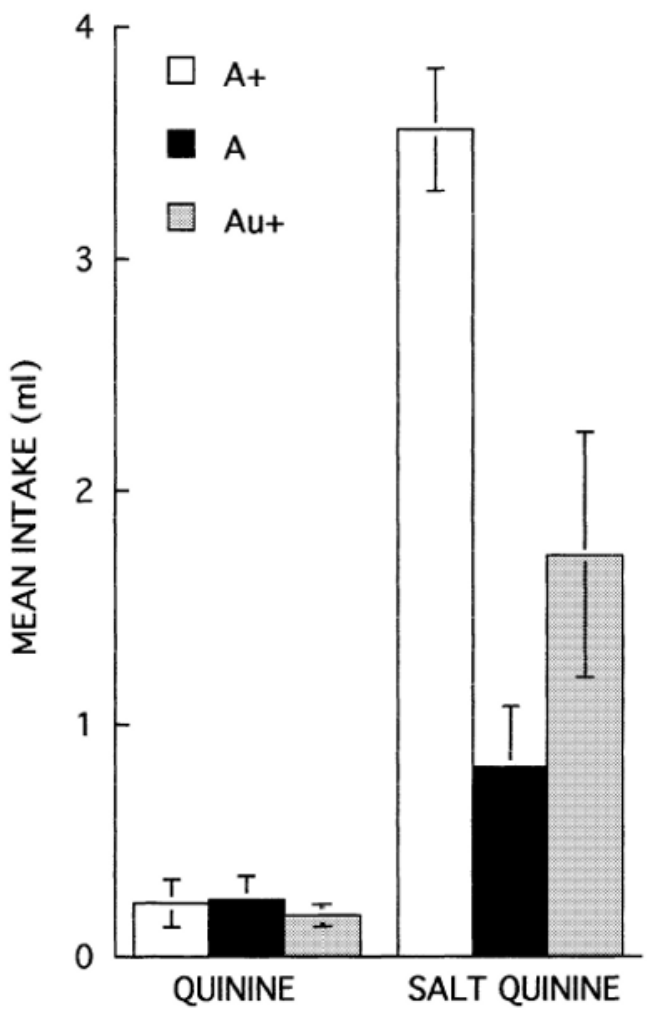

Figure 1. Mean intake of the quinine-alone solution $(Q)$ and of the compound solution salt + quinine (BQ) in the tests of Experiment $1 \mathrm{~A}$.

did not. But B did not reduce the suppression of intake of quinine in Group Au+. This group did not differ from Group A and did differ from Group A+. Preexposure to $A$ and $B$ in the absence of $X$ was insufficient to produce the (negative) summation effect.

\section{Experiment 1B}

\section{Method}

Subjects and Apparatus. The subjects were 16 naive LongEvans rats, 8 males and 8 females, approximately 3 months old at the beginning of the experiment. They were divided, according to sex and consumption during the preexposure phase, into two groups, Group B+ and Group $+B$, of 4 males and 4 females each. The rats were caged in pairs or in groups of 3 and were maintained under the same conditions as in Experiment 1A. The different solutions and the apparatus were the same as in Experiment 1A.

Procedure. The schedule of water deprivation, the preliminary phase, and the preexposure phase were identical to Experiment 1A, as well as the general procedure of the experiment (see Table 1 for condensing tables). On the preexposure phase, all rats had access to the two compound solutions, AX and BX. The next phase was the conditioning one. On the 1st and 3rd days of this phase, the rats in Group B+ had access to salt (B), and the rats in Group $+\mathrm{B}$ had access to tap water; and approximately 5-10 min after consumption, all rats received an intraperitone al injection of $\mathrm{LiCl}(0.15 \mathrm{M}$, $10 \mathrm{ml} / \mathrm{kg}$ ). On the 2nd and 4th days, the rats in Group B+ had access to water, and the rats in Group B had access to the salt solution
(B). The following day, all rats received salt (B) in order to evaluate the aversion for it. After 2 days of rest, all rats were conditioned to quinine (Q). Then, after 1 day of rest, the rats had access to the quinine solution $(\mathrm{Q})$ in order to evaluate the aversion for it. The summation phase constituted the next and last day of the experiment. The rats had access to a compound solution formed by acid-quinine (AQ).

\section{Results and Discussion}

In the preexposure phase, in the last two presentations of the acid-saccharine compound, Groups B+ and B had mean consumptions of 3.7 and $4.2 \mathrm{ml}$, respectively $\left(F_{\mathrm{s}}<\right.$ 1.0 ); in the last two presentations of the salt-saccharine compound, the mean consumption was $9.9 \mathrm{ml}$ for both groups. In the conditioning-to-B phase, the mean consumptions for the salt solution, averaging the two presentations of it, for Groups B+ and B, were 6.6 and $7.6 \mathrm{ml}$, respectively $(F<0.5)$. In the test-to-B day, the mean consumptions of the salt solution for Groups $\mathrm{B}+$ and $\mathrm{B}$ were 2.2 and $8.5 \mathrm{ml}$, respectively $[F(1,14)=13.62, p<.01]$.

Figure 2 shows the mean consumption of the quinine solution $(\mathrm{Q})$ in the test day and of the acid-quinine solution (AQ) in the summation test day. On the test-to-quinine day, the intake of the groups did not differ $(F<1.5)$. On the summation test day, the analysis showed that the groups did differ $[F(1,14)=13.86, p<.01]$. These results show a clear summation effect: Only in the B+ Group did the presence of $\mathrm{A}$ in the summation test reduce the suppression of intake of quinine. Therefore, A seemingly acted as conditioned inhibitor in Group B+ but not in Group B.

\section{Experiment 1C}

\section{Method}

Subjects and Apparatus. The subjects were 23 Long-Evans rats, 11 males and 12 females, approximately 5-months old at the beginning of the experiment, that had previously participated in a swimming-pool experiment. They were divided into two groups, $\mathrm{A}+(5$ males and 6 females) and A (6 males and 6 females), matched for sex, and consumption on the preexposure phase. Two rats from the A+ Group ( 1 male and 1 female) died during the experimentone of them, for unknown reasons, at the end of the preexposure phase, and the second one after the first injection of $\mathrm{LiCl}$-leaving a total of 4 males and 5 females in this group. The rats were caged and maintained under the same conditions as in the previous experiments. The different solutions and the apparatus were also the same as in Experiments 1A and 1B.

Procedure. The schedule of water deprivation, the preliminary phase, and the preexposure phase were identical to Experiments $1 \mathrm{~A}$ and $1 \mathrm{~B}$, as well as the general procedure of the experiment (see Table 1). The conditioning phase lasted 4 days. On the 1 st and $3 \mathrm{rd}$ days of this phase, the rats in Group A+ received the citric acid solution (A), and the rats in Group A had access to tap water; approximately 5-10 min after consumption, all rats received an intraperitoneal injection of $\mathrm{LiCl}(0.15 \mathrm{M}, 10 \mathrm{ml} / \mathrm{kg})$. On the 2 nd and 4th days, the rats in Group $\mathrm{A}+$ had access to water, and the rats in Group A received citric acid solution (A). The following day, all rats had access to the citric acid solution (A) in order to evaluate the aversion for it. Then, the retardation phase began. All rats had access to the salt solution for 2 alternate days; between these days, 


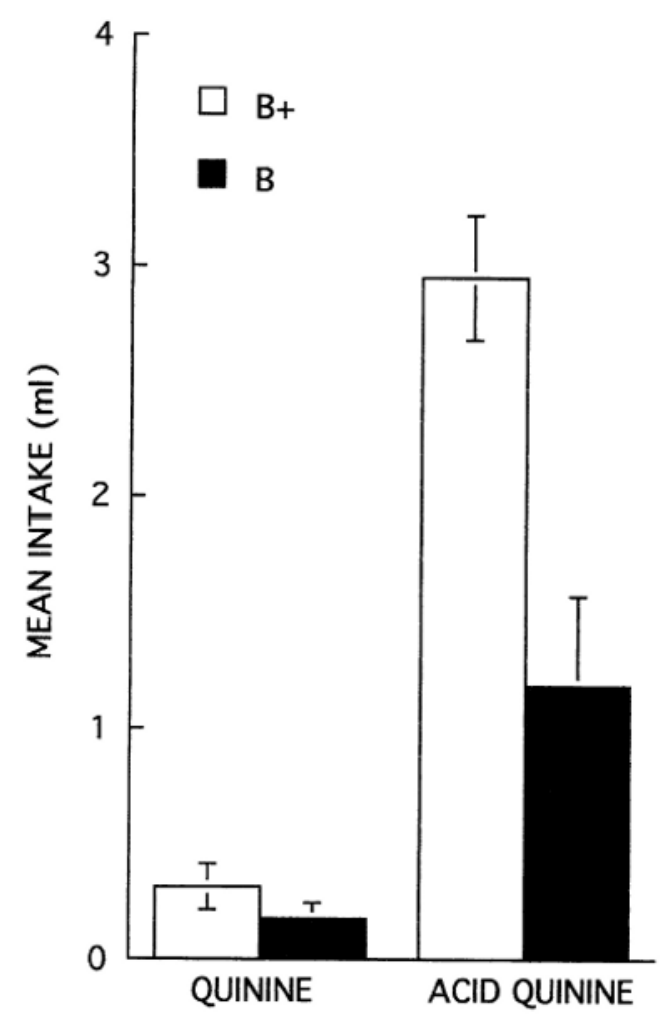

Figure 2. Mean intake of the quinine-alone solution $(Q)$ and of the compound solution acid+quinine (AQ) in the tests of Experiment $1 B$.

they received water in the experimental cages. Approximately 5-10 min after drinking the salt solution, they received an intraperitoneal injection of $\mathrm{LiCl}(0.15 \mathrm{M}, 10 \mathrm{ml} / \mathrm{kg})$.

\section{Results and Discussion}

In the preexposure phase, the mean consumptions for Groups A+ and A in the last two presentations of the acid-saccharine compound (AX) were 3.8 and $3.9 \mathrm{ml}$, respectively $\left(F_{\mathrm{S}}<0.5\right)$. Also in the preexposure phase, in the last two presentations of the salt-saccharine compound, Groups A+ and A had mean consumptions of 11.6 and $11.1 \mathrm{ml}$, respectively $\left(F_{\mathrm{S}}<0.5\right)$. In the conditioning phase, the mean consumptions of the acid solution (A) averaging the two presentations of this solution, were $3.2 \mathrm{ml}$ and $3.8 \mathrm{ml}$ for Groups A+ and A, respectively. These differences were not significant $(F<1)$. In the test-to-A day, the consumptions of the acid solution (A) were 0.2 and $4.0 \mathrm{ml}$ for Groups $\mathrm{A}+$ and $\mathrm{A}$, respectively $[F(1,19)=138.81, p<.01]$.

Figure 3 shows the mean consumptions of salt (B) for the two groups over the course of the retardation test. An analysis of variance (ANOVA), with groups and days as factors, revealed a significant effect of groups $[F(1,19)=$ $6.08, p<.05]$ and days $[F(1,19)=36.65, p<.01]$; the interaction was not significant $(F<1.3)$. In this experiment, Group A+ conditioned an aversion to B more slowly than did Group A, a result that can be attributed to a re- tardation of excitatory conditioning due to prior inhibitory conditioning during preexposure.

\section{EXPERIMENT 2}

In Experiment 1, we replicated the finding that after a long and alternated preexposure to two compound flavors, $\mathrm{AX}$ and $\mathrm{BX}$, which shared a common element, $\mathrm{X}$, conditioning to A (or to B) is sufficient to establish B (or A) as a stimulus that performs like a conditioned inhibitor of the US, passing both summation and retardation tests for inhibition, thereby replicating the findings of Espinet et al. (1995). In Experiments 2 and 3, we wanted to expand the generality of these effects. For this reason, we used a different procedure and scenario (a behavioral preparationspecifically, an auditory discrimination task -in which a set of notes served as cues and fictitious composers served as outcomes, instead of the taste aversion preparation of Experiment 1), humans as subjects (instead of rats), and a sequential presentation of the CS stimuli (instead of simultaneous presentations). Due to the fact that the McLaren et al. (1989) model predicts that initial withincompound associations between $\mathrm{A}$ and $\mathrm{X}$ and between $\mathrm{B}$ and $X$ are necessary to eventually obtain a mutual inhibitory link between $\mathrm{A}$ and $\mathrm{B}$ while presenting $\mathrm{AX}$ and $\mathrm{BX}$, with the last procedural change we intended to see whether the processing of sequentially presented stimuli could affect in the final inhibitory associations. This is important because it has been suggested (Dwyer, Mackintosh, \& Boakes, 1998) that within-compound associations between simultaneously presented stimuli could be a critical factor in obtaining reevaluation effects, whereas within-compound associations between sequentially presented stimuli would favor mediated conditioning.

In Experiment 2, two groups of undergraduate subjects were exposed in Phase 1 to three alternated compound auditory stimuli, XA, XB, and YC, two of which, XA and $\mathrm{XB}$, contained one stimulus in common, $\mathrm{X}$. Each compound stimulus was formed by eight consecutive notes (notes 1-4 were the first stimulus, $\mathrm{X}$ or $\mathrm{Y}$, and notes 5-8 were the second stimulus, either $\mathrm{A}, \mathrm{B}$, or C). In Phase 2, all subjects received four compound melodies, QS, RA, SM, and LR, which were differentially assigned to two composers, Composer Black and Composer Red. The subjects were told to guess which of the two composers was responsible for each compound melody: Specifically, in the presence of each compound melody, they had to make a choice between two response buttons, one black (indicating Composer Black) and the other red (indicating Composer Red). Feedback was always given after each buttonpress. For half of the subjects, after the presentation of either RA or QS, pressing the black button (i.e., choosing Composer Black) was acknowledged as correct and pressing the red button (i.e., choosing Composer Red) was incorrect; after LR or SM, pressing the black button (i.e., choosing Composer Black) was acknowledged as incorrect and pressing the red one (i.e., choosing Composer Red) was correct. Exactly the reverse 


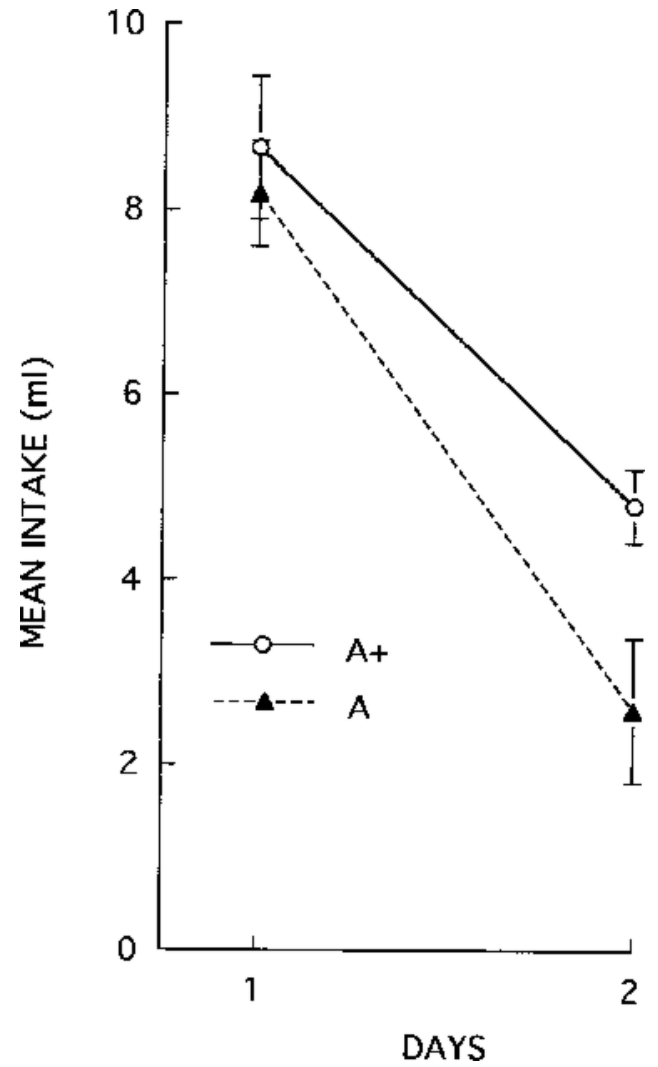

Figure 3. Mean intake of salt solution (B) over the 2 days of conditioning in the retardation test of Experiment 1C.

was correct for the other half of the subjects. Therefore, for all the subjects, the two melodies $\mathrm{R}$ and $\mathrm{S}$ were specifically conditioned to be ambiguous. During Phase 3, without feedback, one group of subjects received the compound melodies QS, SM, and QB, and the second group received QS, SM, and QC. As in Phase 2, they were asked to guess which of the two composers was responsible for each compound melody. QB and QC were the crucial test trials, and the choice of the composer associated with A (either Red or Black) was measured. Because it was expected that B performed as a conditioned inhibitor for the composer associated with A (referred to as Composer 1, C1), the prediction for the test trials was to obtain a smaller preference for Composer 1 with QB than with QC (a summation test for inhibition).

\section{Method}

Subjects. The subjects were 66 psychology subjects at the University of Barcelona, with an average age of 22 years. They were assigned at random to one of two groups: Group Experimental (with 33 subjects) and Group Control (with 33 subjects). The subjects were naive about the hypothesis of the experiment in which they participated as volunteers.

Apparatus. The experiment was run in a large room $(9 \times 5 \times$ $3 \mathrm{~m}$ high). A PC 386 computer, an interface, and six individual small compartments inside the room were used. Each compartment was equipped with one control box $(9 \times 15.5 \times 6 \mathrm{~cm}$ high $)$ placed on a shelf, a set of headphones, and a chair from which the subject could comfortably reach the box. The box had two response buttons (each $1 \mathrm{~cm}$ in diameter), one colored black to the left and one colored red to the right. Above the buttons and in the middle of the box, there were two small bulbs (each $1 \mathrm{~cm}$ in diameter), one above the other. The upper bulb could be illuminated red, and the lower one could be illuminated green. Both bulbs could be illuminated simultaneously. The computer was placed outside the individual compartments, and it was programmed to execute three tasks: to generate sounds, to collect the responses of the subjects on the two buttons of the box through the interface, and to register the reaction time of the subjects to press the response buttons. The auditory stimuli were presented through the headphones to the subjects.

Procedure. A between-groups design was used in this experiment (see Table 2). It lasted 3 days, and the subjects were run in squads of 5 or 6 each. The experiment had three phases: Phase $1=$ preexposure (Days 1, 2, and 3); Phase 2 = discrimination learning (Day 3); and Phase 3 = test trials (Day 3). At the beginning of each day, the subjects received brief and specific instructions from the experimenter. Phase 1 and Phase 2 were identical for all the subjects. In this experiment, melodies $\mathrm{B}$ and $\mathrm{C}$ were counterbalanced.

During preexposure, three compound melodies, $\mathrm{XA}, \mathrm{XB}$, and YC, were presented interspersed, 40 times each on Days 1 and 2, and five times each on Day 3. Each compound melody was formed by eight consecutive notes (notes 1-4 for the first melody, and notes 5-8 for the second melody) and lasted $5.33 \mathrm{sec}(666.67 \mathrm{msec}$ each note). The compound stimuli were separated by an interval of $1.5 \mathrm{sec}$. All sets of four notes (single melodies) were equal in timbre, intensity, and duration (invariable values). The subjects were told to listen carefully to these stimuli. Discrimination learning in Phase 2 consisted of the presentation, in a semi-random order, of four types of compound melodies, QS, RA, SM, and LR, 24 times each. A trial consisted of the presentation of one of these compounds. Then, a warning signal appeared for $0.5 \mathrm{sec}$ (the illumination of the two small lightbulbs simultaneously); at the end of it, the subjects were allowed $4 \mathrm{sec}$ to make a response. They had to press either the black button or the red one. After their response, the subjects received the feedback stimulus for $1 \mathrm{sec}$. The green light was illuminated following a correct response, and the red light was illuminated following an incorrect response. Following feedback, there was a $1.5-\mathrm{sec}$ interval before the next trial began. For all subjects, compound melodies QS and RA indicated a specif ic composer (C1: Composer Red or Black, counterbalanced), and compound melodies SM and LR indicated the alternative composer (C2). The subjects were specif ically encouraged to be spontaneous but not to hurry. On test, the task was identical to the second phase, but no feedback was administered. Four compound melodies were used in this phase: QS, SM, QB, and QC. Each subject was presented with three of them only, twice each. QS and SM were presented to all subjects, and they constituted known discrimination trials. The final stimulus was different for the two groups: QB for the experimental subjects, and QC for the control ones. QB and QC constituted the critical test trial. For half of the experimental subjects, the order of presentation of trials during Phase 3 was QS, SM, QB, QB, SM, QS; for the other half, the order was QB, SM, QS, QS, SM, QB. Similarly, for half of the control subjects, the order of presentations was QS, SM, QC, QC, SM, QS; for the other half, the order was QC, SM, QS, QS, SM, QC. In the presence of QS and $\mathrm{SM}$, on discrimination trials, the choice ratio for the correct composer was measured; in the presence of $\mathrm{QB}$ and $\mathrm{QC}$, on test trials, the choice ratio for Composer 1, the composer associated with $\mathrm{A}$, was measured.

On discrimination trials, with QS and SM, we expected no differences between groups, with all subjects responding correctly in the presence of QS (i.e., Composer 1 correct) and SM (i.e., Composer 2 correct). But, on test trials, because Q indicated Composer 1 in Phase 2 for all the subjects (i.e., the same composer associated 
Table 2

Design of Experiments 2, 3, and 4

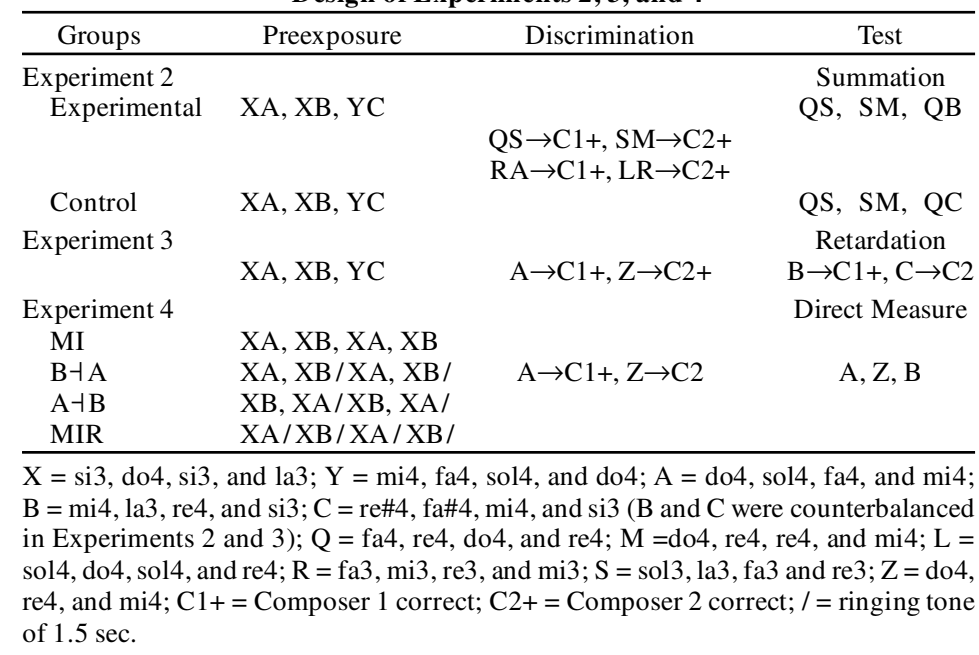

with A), our predictions were that the choice for Composer 1 would be weaker when QB was presented (in the experimental group) than when QC was presented (in the control group).

\section{Results and Discussion}

During Phase 3, on discrimination trials, the mean choice ratios for the correct composer by the experimental group were .73 with QS (i.e., Composer 1) and .76 with SM (i.e., Composer 2). For the control group, the ratios were .75 with QS (i.e., Composer 1 ) and .84 with SM (i.e., Composer 2). An ANOVA with groups and stimuli as factors, showed that no main effect or interaction was significant $\left(F_{\mathrm{S}}<1.5\right)$.

The choice ratios for Composer 1 were .58 and .77 with QB (experimental group) and with QC (control group), respectively. The groups clearly differed, with less preference for Composer 1 (the composer previously associated with $\mathrm{A}$ ) in the presence of $\mathrm{QB}$ than in the presence of QC $[F(1,64)=4.04, p<.05]$.

In conclusion, the groups in Experiment 2 did not differ on the discrimination trials, QS and SM (where a clear preference for the correct composer was observed), but they did on the QB and QC trials. In the first case, for the experimental subjects, B performed as a conditioned inhibitor of Composer 1 in comparison with control subjects (for whom $\mathrm{C}$ hardly affected the result expected based on $\mathrm{Q}$ alone). Notably, in spite of the sequential presentation of the stimuli, a clear summation effect was found, contrary to the suggestion of Dwyer et al (1998).

\section{EXPERIMENT 3}

Experiment 3 used a within-subjects design. The general procedure was very similar to Experiment 2 . In preexposure, during Phase 1, the subjects were exposed to three alternated compound melodies, XA, XB, and YC.
In Phase 2, they received two single melodies, $\mathrm{A}$ and $\mathrm{Z}$ (each melody formed by four consecutive notes), which were differentially assigned to the two composers, Black and Red. The subjects were told to guess which of the two composers produced each melody, pressing one of two buttons, black or red, in the presence of that melody. Feedback was always given after each buttonpress. During Phase 3, all subjects were presented with two new stimuli, B and C (the test trials), intermixed with $\mathrm{A}$ and $\mathrm{Z}$ (the discrimination trials). $\mathrm{B}$ was assigned to Composer 1 (the composer associated with $\mathrm{A}$ ), and $\mathrm{C}$ was assigned to Composer 2 . The question of interest was whether $B$ would condition less rapidly than $\mathrm{C}$ (a retardation test for inhibition).

\section{Method}

Subjects and Apparatus. The subjects were 19 subjects of psychology at the University of Barcelona, with an average age of 20 years. They were naive about the hypothesis of the experiment in which they participated as volunteers. The experiment was run in the same room and with the same equipment as in Experiment 2.

Procedure. A within-subjects design was used in this experiment (see Table 2), which had a general procedure very similar to Experiment 2. As in Experiment 2, B and $\mathrm{C}$ were counterbalanced, as were the composers, Black and Red. The experiment lasted 2 consecutive days, and the subjects were run in squads of 5 or 6 each. Day 1 consisted of the alternate presentation of three compound stimuli, XA, XB, and YC, 20 times each. Day 2 consisted of three phases: preexposure (identical to Day 1), discrimination learning, and test. Discrimination learning consisted of the presentation of two single stimuli, A and Z. Each of them was formed by four consecutive notes and lasted $2.66 \mathrm{sec}$. A and $\mathrm{Z}$ were presented in a semi-random order, 16 times each. Stimuli B and $C$ were presented four times each. They were intermixed with the last four presentations of $\mathrm{A}$ and $\mathrm{Z}$. Trials with $\mathrm{B}$ and $\mathrm{C}$ constituted the retardation phase, Phase 3. Both a discrimination trial and a test trial consisted of the presentation of one stimulus (A, Z, C, or B) followed by $0.5 \mathrm{sec}$ of the warning signal (the two small lightbulbs simultaneously illuminated); at the end of the warning signal, the subjects were allowed $4 \mathrm{sec}$ to press either the black button or the red one. 


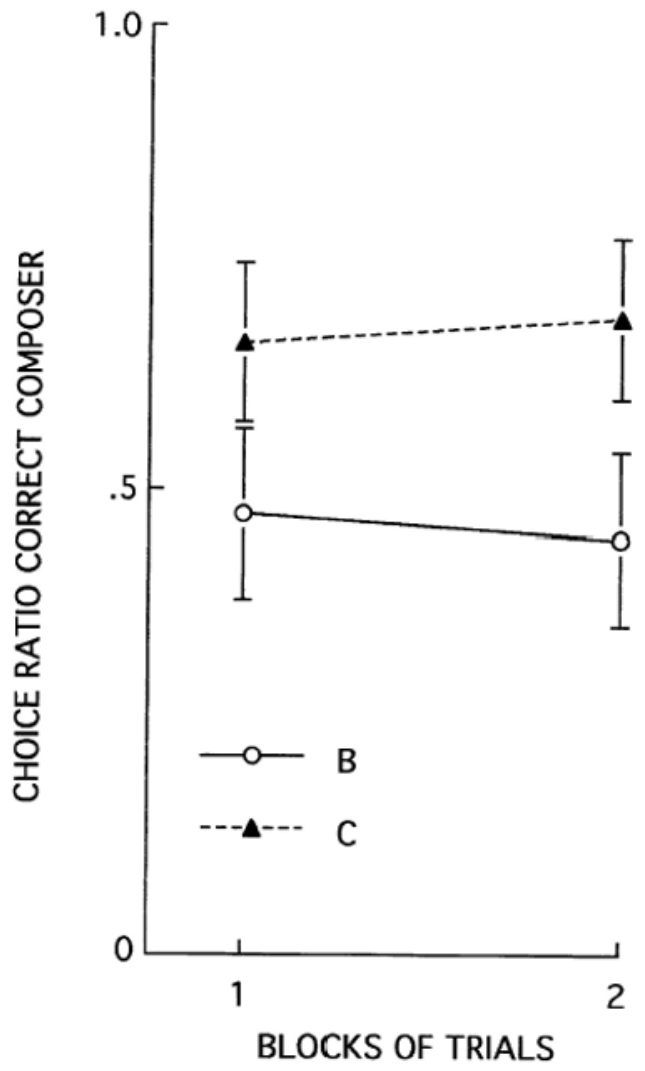

Figure 4. Choice ratio for the correct composer in the presence of the test stimuli, B and C, of Experiment 3.

After their response, the subjects received a feedback stimulus for $2 \mathrm{sec}$. The green light was illuminated following a correct response, and the red light was illuminated following an incorrect response. Following feedback, there was a 1.5 -sec interval before the next trial began. For all subjects, $\mathrm{A}$ and $\mathrm{C}$ indicated Composer 1 correct, and $\mathrm{Z}$ and $\mathrm{B}$ indicated Composer 2 correct. As in Experiment 2, the subjects were specifically encouraged to be spontaneous but not to hurry. Both on the discrimination trials (with $\mathrm{A}$ and $\mathrm{Z}$ ) and on the test trials (with B and C), the choice ratio for the correct composer in the presence of the stimuli was measured.

\section{Results and Discussion}

During Phase 2 (the discrimination training), on the last two presentations of $\mathrm{A}$ and $\mathrm{Z}$, the correct composer was chosen $97.37 \%$ correctly in the presence of $A$, and $100 \%$ correctly in the presence of $\mathrm{Z}$. These differences were not significant $(F<1.0)$.

Figure 4 shows the choice ratios for the correct composer in the presence of the test stimuli, B and C, in two blocks of two trials each. The preference for the correct composer appears to vary depending on the stimulus. There is a smaller preference for the correct composer in the presence of B (i.e., Composer 1) than in the presence of C (i.e., Composer 2). An ANOVA, with stimuli and blocks of two trials as factors, confirmed these impres- sions. The only significant effect was stimuli $[F(1,18)=$ $4.85, p<.05]$. Neither the main effect of blocks of trials nor the interaction of stimuli $\times$ blocks was significant $\left(F_{\mathrm{s}}<0.1\right)$. In conclusion, with a within-subjects design, Stimulus B performed as a conditioned inhibitor for the correct composer in comparison with Stimulus C: The subjects learned the association $\mathrm{C} \rightarrow$ Composer 2 faster than the association $\mathrm{B} \rightarrow$ Composer 1 (the composer associated with A). Thus, a clear retardation was observed.

\section{EXPERIMENT 4}

Experiment 4 was designed to tentatively clarify, within the McLaren et al. (1989) model, which of the two possible mechanisms (Espinet et al., 1995, or Bennett et al., 1999) can best explain the results found in Experiments 2 and 3. The Espinet et al. mechanism predicts that Melody B would become a conditioned inhibitor of the composer associated with Melody A because its level of activation in the conditioning phase should have been negative due to the high internal input of $\mathrm{B}$ because of the presentation of A. Conversely, Bennett et al's. mechanism would predict that, in the test phase, B would activate a negative representation of $\mathrm{A}$ and also of the composer associated with it in the previous conditioning phase, with the consequence of a negative impact on the subject's preferences for that composer. In Experiment 4, a distractor stimulus (a noise) was used during preexposure as a new procedure to obtain differential inhibitory associations between A and B among the groups.

In some sequence learning studies, it has been repeatedly observed that the presence of an irrelevant stimulus causes a deficit in the subsequent recall of the sequence (Colle \& Welsh, 1976; Jones, 1993). However, in related experiments, it has been observed that when subjects are not specifically asked to learn a sequence, the performance of alternative tasks does not affect in the subsequent recall of the sequence (Cleeremans, 1997; Jiménez \& Méndez, 1999). In order to explain these apparently contradictory results, it has been argued that the processes of explicit learning, in which a mental effort is required, are dependent on attentional control, whereas the processes of implicit learning are not (Schneider \& Shiffrin, 1977). Implicit learning has been described as an automatic associative process established among all the simultaneously active representations in short-term memory (Frensch \& Miner, 1994; Stadler, 1995). Therefore, it is possible that the presentation of an irrelevant noise during the preexposure phase could result in a deficit for learning the musical sequences because, in this phase, the subjects are asked to pay a lot of attention to these sequences. The presentation of the irrelevant stimulus could distract the subjects'attention. Consequently, they may not fully process the stimuli that precede it. If this is accepted, the effect of such a distractor within the McLaren et al. 


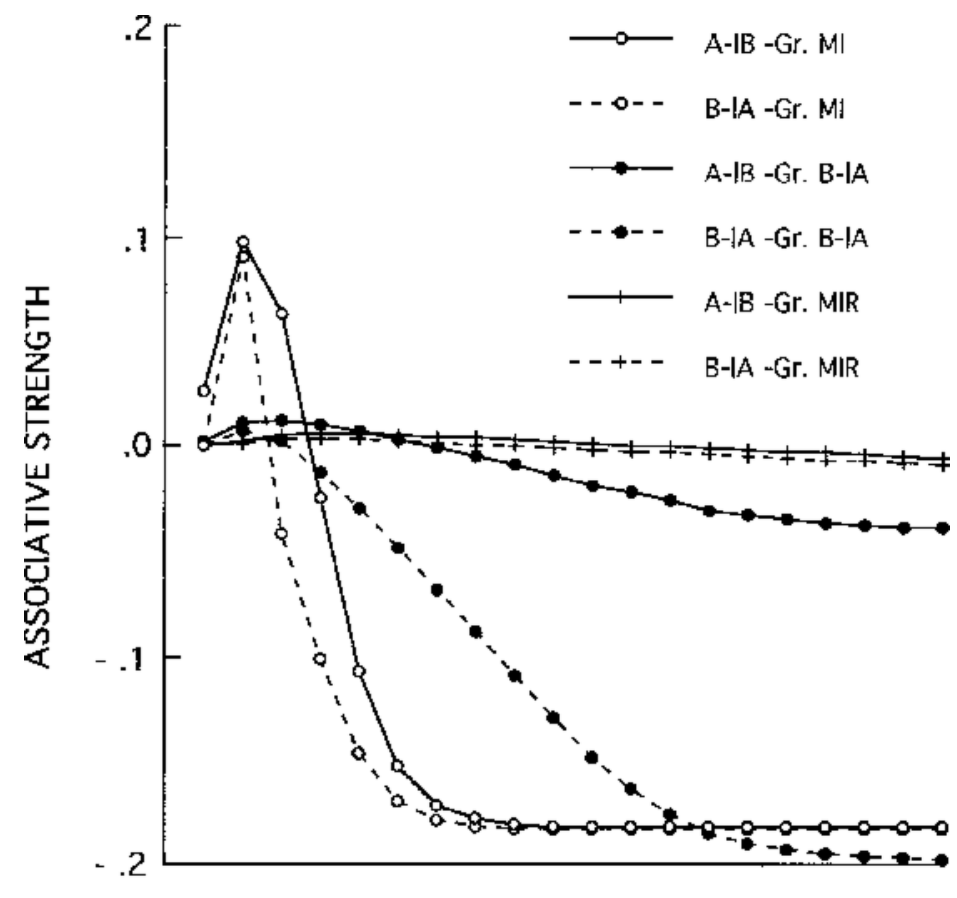

AMOUNT OF PREEXPOSURE

Figure 5. Simulation of the preexposure phase for three of the groups of Ex-

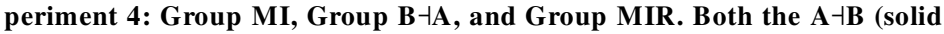
line) and the $B \dashv A$ (dotted line) inhibitory association have been calculated for the three groups (see text for further explanation).

(1989) model could be to reduce the magnitude of the external input of the stimuli that immediately precede the distractor.

Other theories of associative learning, like Wagner's SOP, can also explain these effects. According to Wagner (1981), the presentation of a posttrial stimulus affects the stimuli that immediately precede the posttrial event. It produces a change from the A1 memory state to the A2 memory state in a large fraction of the representational target stimulus elements. Due to this, the development of the excitatory associations among them will be interrupted, because associations are formed only among the elements that are simultaneously activated in the A1 state. One implication is that the knowledge acquired concerning the stimuli that precede the posttrial event is weaker than what would otherwise have been acquired, because a processing deficit will be produced (in the General Discussion section, there is a more detailed explanation of this model).

Suppose that a group of subjects receive alternated exposures to Stimuli XA and XB, with XB presentations always immediately followed by a noise, but never the XA presentations. The noise would mainly reduce the processing of $\mathrm{B}$, the last stimulus presented, leaving the processing of $\mathrm{X}$ little affected. This might influence the excitatory within-compound $\mathrm{X} \rightarrow \mathrm{B}$ association, but not the $\mathrm{X} \rightarrow \mathrm{A}$ one. The main consequence of this would be that a weaker $\mathrm{X} \rightarrow \mathrm{B}$ within-compound association will be formed during preexposure in comparison with the $X \rightarrow A$ within-compound association. Therefore, on XA presentations, Stimulus X should activate a representation of a weak B (because the within-compound association $\mathrm{X} \rightarrow \mathrm{B}$ is weak), which, when applying the equation for the changing of weights (McLaren et al., 1989), would allow a residual inhibitory association from A to B only. Conversely, on XB presentations, Stimulus X should activate a good representation of A (because the withincompound association $\mathrm{X} \rightarrow \mathrm{A}$ is strong), which, when applying the equation for the changing of weights, would allow a strong inhibitory association from B to A. It is worth mentioning that because implicit learning is presumably automatic, a distractor stimulus should eliminate neither the activation reached in B's representation nor the activation of any other representation (of A and X, for example). Thus, the associative processes in which all the activated representations could intervene will continue their course as normal and until they reach a resting state.

Although we admit that this explanation is not exempt from ambiguity, a simulation was performed to test the role of a distractor. The effect of such a stimulus was (arguably) simulated by reducing the magnitude of the stimuli that would have preceded the supposed distractor. Three groups were simulated: Group MI (mutually inhibitory), Group B $\dashv$ A, and Group MIR (mutually in- 
hibitory residual). In Group MI, the compound stimuli $\mathrm{XA}$ and XB were alternately presented. In Group $\mathrm{B} \dashv \mathrm{A}$, these compound stimuli were equally presented as in Group MI, but in each XB presentation, the magnitude of Stimulus B was reduced. In Group MIR, the compound stimuli were presented as in Group MI, but, in each presentation, either XA or XB, the magnitude of both stimuli, $A$ and $B$, was reduced. The results of this simulation can be seen in Figure 5, which presents two inhibitory measures for each group, from $A$ to $B$ (i.e., $A \dashv B$ ) and from $B$ to $A$ (i.e., $B \dashv A)$. Group $M I(A \dashv B$ and $B \dashv A)$ shows a bidirectional inhibitory association between $\mathrm{A}$ and $\mathrm{B}$, which is clearly reduced in Group MIR ( $\mathrm{A} \dashv \mathrm{B}$ and $\mathrm{B} \dashv \mathrm{A})$, for which practically no inhibitory association between $A$ and B is observed. Most important, Group B $\dashv \mathrm{A}$ shows a strong inhibitory association from $B$ to $A$ (when measuring the $\mathrm{B} \dashv \mathrm{A}$ association), but a weak association from $\mathrm{A}$ to $B$ (when measuring the $A \dashv B$ association). Thus, the presentation of stimuli reduced in intensity seems to be a plausible means of obtaining differential inhibitory associations between A and B among the groups, while alternately preexposing $\mathrm{XA}$ and $\mathrm{XB}$, within the framework of the McLaren et al. (1989) model.

One aim of Experiment 4 was to see whether this new procedure would be successful with subjects and functionally equivalent to the long intertrial intervals used by Bennett et al. (1999). In this experiment, a distractor stimulus (a noise) was used as a new approach to illuminating the underlying mechanism in Experiments 2 and 3. Admittedly, Experiment 4 hinged on our assumption that a distractor stimulus has an effect equivalent to reducing the intensity of the immediately preceding stimulus (i.e., melody). There were four groups (Group MI, Group B $\dashv$ A, Group $A \dashv B$, and Group MIR) and three phases (preexposure, discrimination, and test). The discrimination and test phases were identical for all subjects. During preexposure, the four groups were alternately preexposed to the compound stimuli XA and XB. In Group MI, this phase was exactly as in Experiment 3, thus allowing good within-compound associations to form between $\mathrm{X}$ and $\mathrm{A}$ and between X and B. In Group B $\dashv \mathrm{A}$, after each XB presentation, a noise was presented. The noise was expected to interfere with the formation of an association from $X$ to B (but not from $X$ to $A$ ). In Group $A \dashv B, X A$ compounds were immediately followed by a noise. This stimulus would interfere with the formation of an association from $\mathrm{X}$ to A (but not from X to B). Finally, in Group MIR, each compound stimulus, either XA or XB, was immediately followed by a noise. The noise was expected to interfere with the formation of an association both from $\mathrm{X}$ to $\mathrm{A}$ and from $\mathrm{X}$ to $\mathrm{B}$. Applying the equation for changing of weights of the McLaren et al. (1989) model to the four groups, differential inhibitory associations between the unique elements of both compound stimuli, A and B, were anticipated: in Group MI, mutual inhibitory associations between A and B; in Group B $\dashv \mathrm{A}$, an inhibitory association from $B$ to $A$ stronger than that from $A$ to $B$; in Group $\mathrm{A} \dashv \mathrm{B}$, an inhibitory association from $\mathrm{A}$ to $\mathrm{B}$ clearly stronger than that from B to A; and in Group MIR, attenuated inhibitory associations between $\mathrm{A}$ and $\mathrm{B}$.

During Phase 2 (discrimination), two single stimuli, A and Z, were presented. As in Experiment 3, the subjects were told to guess which of two composers (Black and Red) was responsible for each melody by pressing one of two buttons. Melody A indicated that Composer 1 was correct, and Melody Z indicated that Composer 2 was correct. Feedback was given after each buttonpress. During Phase 3 (test), without feedback, Stimulus B was presented, intermixed with presentations of Stimuli A and Z. Melody B trials constituted the crucial test trials, whereas $\mathrm{A}$ and $\mathrm{Z}$ allowed assessment of the discrimination trials. As in Phase 2, the subjects were told to guess which of the two composers had created each melody (A, $\mathrm{B}$, and $\mathrm{Z}$ ) by pressing one of the two buttons. On the discrimination trials with $\mathrm{A}$ and $\mathrm{Z}$, the number of responses corresponding to the correct composer was measured. On the crucial test trials with $\mathrm{B}$, the preference for Composer 1 (the composer associated with A) relative to chance was measured in each group.

The Espinet et al. (1995) mechanism predicts that Melody B would become a conditioned inhibitor of the composer associated with Melody A because its level of activation in the conditioning phase should have been negative due to the high internal input of B because of presentation of $\mathrm{A}$. This mechanism permits a negatively activated stimulus to change its associative strength. If it is correct, the preference for Composer 1 should have been reduced in Groups MI and $\mathrm{A} \dashv \mathrm{B}$ relative to Groups MIR and $\mathrm{B} \dashv \mathrm{A}$, which should perform at the level of chance. Conversely, the simpler Bennett et al. (1999) mechanism does not allow that a negatively activated stimulus can change its associative strength. Therefore, this mechanism would predict that in the test phase, the mutual inhibitory associations formed between Melody B and Melody A during preexposure would allow $\mathrm{B}$ to activate a negative representation of $\mathrm{A}$ and also of the composer now associated with it, with the consequence of a negative impact on the subject's preferences for that composer. If it is correct, we expected that there would be a smaller preference for Composer 1 in Groups MI and B $\dashv \mathrm{A}$ than in Groups MIR and $\mathrm{A} \dashv \mathrm{B}$, for which performance should appear at the level of chance.

\section{Method}

Subjects and Apparatus. The subjects were 50 psychology subjects at the University of Barcelona, with an average age of 22 years. They were assigned at random into four groups: Group MI

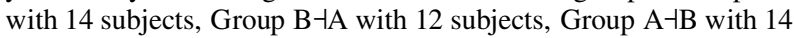
subjects, and Group MIR with 10 subjects. The subjects were naive about the hypothesis of the experiment in which they participated as volunteers. The experiment was run in the same room and with the same equipment as in Experiments 2 and 3.

Procedure. A between-groups design was used in this experiment (see Table 2) that lasted 3 consecutive days. The subjects were run in squads of 5 or 6 each, with a few exceptions. The experiment had three phases: preexposure (Days 1 and 2) and discrimination learning and test (Day 3). Both at the beginning of each day and also of each phase, the subjects received brief and specif ic instruc- 


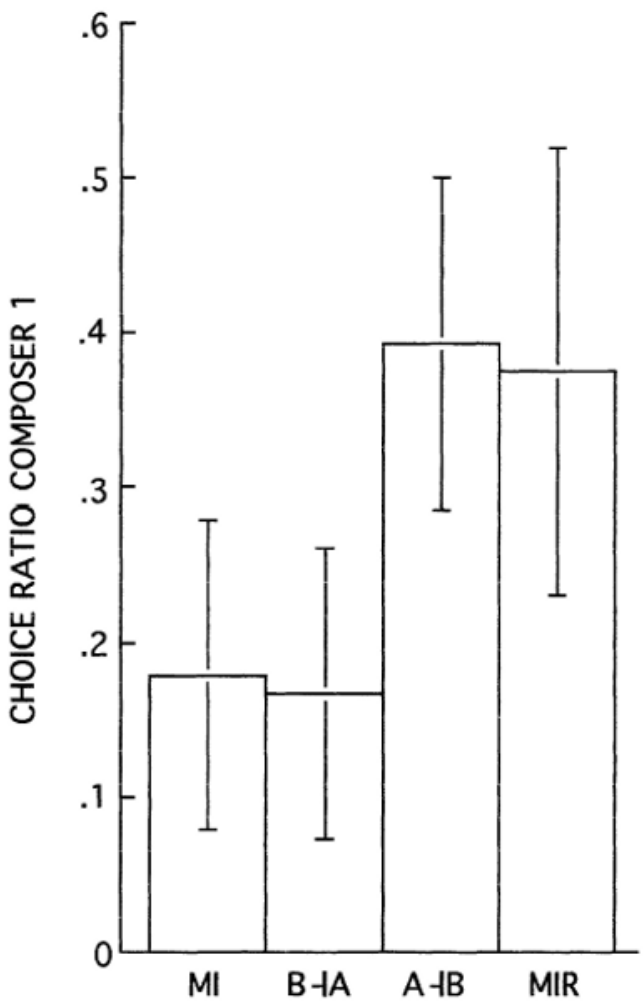

Figure 6. Choice ratio for Composer 1 in the presence of $B$ for the four groups of Experiment 4.

tions from the experimenter (see Appendix B for the specific instructions of this experiment).

On Days 1 and 2, preexposure, two compound stimuli, XA and $\mathrm{XB}$, were presented, 40 times each. Each compound stimulus was formed by eight consecutive notes (notes 1-4 serving as the first stimulus, and notes 5-8 served as the second stimulus) and lasted $4.81 \mathrm{sec}(600.0 \mathrm{msec}$ each note). There was a pause of $0.01 \mathrm{sec}$ between the common element of each compound stimulus, $\mathrm{X}$, and either $\mathrm{A}$ or $\mathrm{B}$, the unique elements, in order to facilitate their discrimination. For Group MI, the compound stimuli XA and XB were alternately presented. For Group $\mathrm{B} \dashv \mathrm{A}$, the presentations were $\mathrm{XA}$ first and then XB. After each XB presentation, there was a ringing

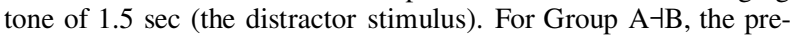
sentations were XB first and then XA. After each XA presentation, there was a ringing tone of $1.5 \mathrm{sec}$ (the distractor stimulus). For Group MIR, the compound stimuli were presented alternately and, after each compound stimulus, either $\mathrm{XA}$ or $\mathrm{XB}$, there was a ringing tone of $1.5 \mathrm{sec}$ (the distractor stimulus). The subjects were told to listen carefully to these stimuli. Day 3 had three parts: preexposure, which was very brief and during which each group received five presentations of each compound stimulus exactly as in the previous days; and discrimination learning and test, which were conducted on Day 3 only and were identical for all subjects and which consisted of the presentation of two single stimuli, A and $\mathrm{Z}$, in a semirandom order, 20 times each, with a maximum of three consecutive presentations of the same stimulus. A trial consisted of the presentation of one stimulus (A or Z) followed by $0.5 \mathrm{sec}$ of a warning signal (the red light and the green light simultaneously illuminated); at the end of the warning signal, the subjects were allowed $4 \mathrm{sec}$ to press either the red button or the black one. Pressing the red button and the black button was counterbalanced with respect to composers. After each response, the subjects received a feedback stimulus (a green light after a correct choice, and a red light after an incorrect choice) for $1.5 \mathrm{sec}$. Following feedback, there was a 1.5sec interval before the next trial began. During Phase 3, the test phase, Stimulus B was presented twice, intermixed with two presentations of $A$ and two presentations of Z. No feedback was presented. Trials with $\mathrm{A}$ and $\mathrm{Z}$ constituted discrimination assessment trials, and trials with B constituted the critical test trials. For all subjects, a B trial always followed two previous trials, one with A and one with $\mathrm{Z}$. The order of trials presentation was $\mathrm{A}, \mathrm{Z}, \mathrm{B}, \mathrm{Z}, \mathrm{A}, \mathrm{B}$. The choice ratio for the correct composer was measured in the presence of $\mathrm{A}$ and $\mathrm{Z}$, whereas the choice ratio for Composer 1 was measured in the presence of $\mathrm{B}$.

\section{Results and Discussion}

During Phase 3, the mean choice ratios for the correct composer for Group MI were .86 with A and .93 with Z; for Group $\mathrm{B} \dashv \mathrm{A}$, they were .83 with $\mathrm{A}$ and .79 with $\mathrm{Z}$; for Group A-B, they were .93 with $A$ and .86 with $Z$; and for Group MIR, they were 1.00 with A and .80 with Z. A clear preference for the correct composer was observed in the four groups, both with A and with Z. An ANOVA, with groups and discriminative stimuli $(\mathrm{A}, \mathrm{Z})$ as factors, yielded no main effect or interaction $\left(F_{\mathrm{s}}<3.0\right)$.

Figure 6 shows the choice ratios for Composer 1 in the presence of B for the four groups. As we can see, the groups do differ. Groups MI and B $\dashv$ A do not seem to differ, and both show suppression for Composer 1 in comparison with that of Groups $A \dashv B$ and MIR, which do not seem to differ. Four independent analyses were carried out to see whether the groups did differ in relation to the chance level in their preference for Composer 1 in the presence of Stimulus B. Both Group MI $[t(13)=-3.23]$ and Group $\mathrm{B} \dashv \mathrm{A}[t(11)=-3.55]$ did differ significantly from the chance level, whereas neither Group $\mathrm{A} \dashv \mathrm{B}[t(13)=$ $-1.00]$ nor Group MIR $[t(9)=-0.92]$ did. In conclusion, Stimulus B performed as a conditioned inhibitor for

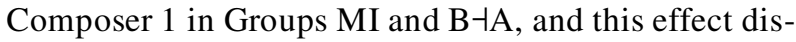

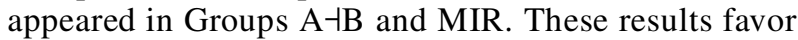
the performance mechanism proposed by Bennett et al. (1999), thus discounting the mechanism proposed by Espinet et al. (1995) to explain that a spaced and alternate preexposure to two compound stimuli, $\mathrm{AX}$ and $\mathrm{BX}$, containing a common element, $X$, followed by the conditioning to A, is sufficient to establish B as a conditioned inhibitor of the US or outcome used to reinforce A. Of course, this conclusion is dependent on the assumption that a prestimulus distractor is equivalent to reducing the intensity of the stimulus.

\section{GENERAL DISCUSSION}

The present set of experiments was intended to demonstrate that the same learning system is responsible for the results found both with nonhuman subjects (Experiment 1) and with human subjects (Experiments 2, 3, and 4). All the experiments were inspired by the McLaren et al. (1989) theory of perceptual learning, a theory that implements variations in associability within an associa- 
tive network employing a modified delta rule (see McLaren \& Mackintosh, 2000, for a review of the research that this model has generated). It is important to mention that this model predicts both second-order excitation and conditioned inhibition. Traditionally, the main tests to measure conditioned inhibition are summation (the reduction in the response normally elicited by an excitatory CS) and retardation (the retardation of excitatory conditioning to the supposed inhibitor; for a recent and critical review of the literature, see Savastano, Cole, Barnet, \& Miller, 1999). In Experiment 1, we used both summation and retardation tests to provide evidence that preexposing rats to two compound stimuli (solutions $\mathrm{AX}$ and $\mathrm{BX}$ ) containing a common element $(\mathrm{X})$ and then pairing A with an US (lithium chloride) is sufficient to establish B as a stimulus that can act as a Pavlovian conditioned inhibitor of that US (for a similar finding using a conditioned-suppression procedure, see Leonard \& Hall, 1999). We also expanded these results to humans using a behavioral preparation, a discrimination task with auditory stimuli sequentially presented. In our human preparation, in order to obtain strong $\mathrm{X} \rightarrow \mathrm{A}$ and $\mathrm{X} \rightarrow \mathrm{B}$ links (the within-compound associations), whenever a compound stimulus was presented, the common element, $\mathrm{X}$, always appeared first and consisted of a set of four consecutive notes that was followed by the unique element, either A or B, both of which were also a set of four consecutive notes. The present data suggest that the procedural differences between the nonhuman and human experiments (i.e., the use of simultaneous presentations of the stimuli vs. sequential presentations, simple Pavlovian stimuli vs. more complex neutral stimuli, a taste aversion preparation versus an auditory discrimination task, and the use of two different species, rats vs. humans) were not critical in obtaining these effects. Both summation and retardation were found in the human experiments (Experiments 2 and 3, respectively), despite the many procedural differences in comparison with the nonhuman preparation. Finally, in Experiment 4, we tentatively explored two accounts that can explain our results within the McLaren et al. (1989) theory. This experiment showed that the explanation in terms of performance proposed by Bennett et al. (1999) was more successful than the explanation proposed by Espinet et al. (1995). This replicated with humans what Espinet et al. first demonstrated with nonhuman animals. (With a similar design, also with humans, although using a medical diagnosis contingency judgment, Graham, 1999, obtained a similar finding.) Notably, Experiment 4 demonstrated that the use of a distractor stimulus might suffice to selectively allow the formation of inhibitory associations.

The Espinet et al. (1995) suggestion of the McLaren et al. (1989) model represents one step further within the kinds of model that allow the associative strength of CS stimuli to change in their physical absence. The modification consists of allowing activations of stimuli to vary between -1 and +1 (instead of between 0 and +1 , as was suggested in the original theory), so as to permit negative activations. We agree with this suggestion. Its main consequence consists of generating two different predictions for the associative change of absent but remembered stimuli. The first prediction refers to an absent stimulus that is remembered in a standard conditioning trial via internal and positive input (i.e., the absent stimulus is expected to occur in this trial). When this is the case, an excitatory association between the absent stimulus and the outcome of that trial is predicted. The second prediction also refers to an absent stimulus that is remembered in a standard conditioning trial but via internal and negative input (i.e., the absent stimulus is not expected to occur in this trial). When this is the case, an inhibitory association between the absent stimulus and the outcome of that trial is predicted (see Appendix A for more details).

Traditional associative theories, such as Rescorla and Wagner's (1972) model and Wagner's SOP model, assume that only the representations of the CS stimuli that are physically present during a learning trial can gain associative strength. But subsequent modifications of both the Rescorla-Wagner equation by Van Hamme and Wasserman (1994) and Wagner's SOP model by Dickinson and Burke (1996; see also Larkin, Aitken, \& Dickinson, 1998) allow that an absent stimulus can vary its associative strength. Although for different reasons, in both cases the associative status of the absent stimulus changes in the opposite manner it would have done if the stimulus had been physically present. By doing so, new findings (e.g., backward blocking and other reevaluation effects) can be explained. In backward blocking, experimental subjects are first exposed to the CS1 + CS2 $\rightarrow$ US pairings and then to CS1 $\rightarrow$ US pairings, whereas control animals do not receive CS $1 \rightarrow$ US pairings. On test, in the presence of CS2, only the control rats show a clear conditioned response in comparison with the experimental animals (for empirical evidence with nonhuman animals, see Miller \& Matute, 1996, and with humans, see Shanks, 1985).

According to Van Hamme and Wasserman (1994), whenever an absent stimulus is remembered on a learning trial, its $\alpha$ value becomes negative. This explains why its associative strength changes in the opposite manner it would have done if being physically present. The original Rescorla-Wagner equation cannot explain any retrospective reevaluation effect. In contrast, Wagner's (1981) SOP model states that the elements of the node that represent a stimulus can be either inactive (I) or in two different states of activation (A1 and A2). When a stimulus is physically present, most of its nodes are active in the A1 state, and, gradually, its elements will decay into the A2 state, a less active state. A node can be activated by activation of another associated node that is in either the A1 state or the A2 state. When this happens, the target node is activated in the A2 state only. According to this model, an excitatory association between two nodes (e.g., representing a CS and a US) will develop when they simultaneously are in the A1 state, and an inhibitory association will develop the node of the CS is in the A1 state 
and the node of the US is in the A2 state, but not vice versa. The main modification proposed by Dickinson and Burke (1996) consists of allowing that excitatory associations will develop whenever two nodes simultaneously are either in the A1 state or in the A2 state and that inhibitory associations will develop whenever they are in different states, either A1-A2 or A2-A1. Equally important is the fact that these authors emphasize the importance of within-compound associations. According to Dickinson and Burke, whenever two neutral stimuli, CS1 + CS2, are within-compound associated, the subsequent presentation of one of them (e.g., CS1) on a standard learning trial, CS $1 \rightarrow \mathrm{US}$, will activate its own node in the A1 state and also the node of the absent CS2 stimulus in the A2 state. That is why the associative strength of CS2, the absent stimulus, will vary in the opposite manner it would have done if being physically present (i.e., activated in the A1 state).

Considering recent research (e.g., Dwyer et al., 1998; Harris \& Westbrook, 1998), it is notable that modern associative theories are gradually accepting that the associative strength of a stimulus can change in its absence (for an alternative account in terms of performance, see Miller \& Matzel, 1988). In Dwyer's et al. (1998) study, it was suggested that a new associative link was formed between the representations of a CS and a US when the two stimuli were physically absent. Many questions related to how absent stimuli can change their associative strength remain to be answered. Backward blocking can be considered as evidence that an absent stimulus can gain associative strength in the opposite manner it would have done if being physically present. But there is also evidence that the memory of an absent stimulus can be equivalent to presenting the stimulus itself, so that it can gain associative strength in the same way it would have done if being physically present (Holland, 1981, 1990). As has been already suggested (Dwyer et al., 1998), this seems to be an intractable theoretical problem. In Holland's (1981) work, experimental and control rats were presented with a tone followed by flavored food pellets. The experimental animals then received the tone followed by an injection of $\mathrm{LiCl}$, whereas the control rats received these two events unpaired. Finally, all animals had free access to the food pellets, and the experimental rats showed a clear aversion to the food, relative to the controls. Holland's explanation was that, during the second phase, the tone activated a memory of the food, and, once activated, the experimental rats associated it with the $\mathrm{LiCl}$ (for an interpretation of this mediated conditioning in terms of Wagner's SOP model, see Hall, 1996). It is difficult to understand results such as backward blocking on one hand and mediated conditioning on the other. More theoretical and empirical work is obviously needed. (For an attempt to reconcile retrospective revaluation of contingency judgments in experiments with humans and mediated inhibitory conditioning with nonhuman subjects, see Graham, 1999.)

In Experiments 1-3 of the present study, spaced alternating preexposure to two compound stimuli, both con- taining a common element, $\mathrm{X}$, and a unique element, either A or B, was followed by conditioning to A. According to Espinet et al. (1995), in the conditioning trial, B (an absent, remembered, and unexpected stimulus) becomes a conditioned inhibitor of the consequence of this trial because the level of activation of $B$ is negative due to the high internal input mediated by A. Presumably, the interaction of the negative activation of $B$ with the positive external input of the US of this trial determines the nature of the association formed between B and the US, which was inhibitory in this case (i.e., mediated inhibitory conditioning). This result was obtained by applying the equation for changing the weight from B to the US (i.e., when applying the delta rule; see Appendix A for more details). If $B$ would have had a positive activation on this trial (thus being an absent, remembered, and expected stimulus), the nature of the association formed between $\mathrm{B}$ and the consequence or outcome of the conditioning trial would have been excitatory (i.e., an excitatory mediated conditioning). A second explanation has been proposed by Bennett et al. (1999): For example, due to the inhibitory associations formed between A and B while preex posing the compound stimuli, $\mathrm{AX}$ and $\mathrm{BX}$, and due to the excitatory association formed between A and the US on Phase 2, then on a retardation test, $\mathrm{B} \rightarrow \mathrm{US}$ (where the US is the same stimulus used in the conditioning phase), B will negatively activate both the unique element A and the US now associated with it. The consequence would be reducing the impact of the US now physically present, and therefore the subject's conditioned response to it. (B will activate a memory of both A and the US. A is an absent, remembered, and unexpected stimulus, but the memory of the US is in contradiction to what the animal experiences. It refers to an unexpected stimulus while it is being presented.) This explanation is in terms of performance and maintains the Espinet et al. (1995) modification of the McLaren et al. (1989) model that the activations vary between -1 and +1 . This explanation allows that an absent, remembered, and expected stimulus could change its associative strength, but, most importantly, it does not allow that an absent, remembered, but unexpected stimulus could do so.

What other mechanisms could be responsible for the results of the summation and retardation experiments presented here? Dickinson and Burke's (1996) modification of Wagner's (1981) SOP model allows an alternative explanation of both effects without resorting to inhibitory associations between neutral stimuli (see Leonard \& Hall, 1999). According to Dickinson and Burke, on the A $\rightarrow$ US conditioning trial, A would activate $X$ 's nodes into the A2 state due to the within-compound association between $\mathrm{A}$ and $\mathrm{X}$ already formed during preexposure, so that $\mathrm{X}$ should gain inhibitory associative strength with the outcome of this trial. Then, in the test phase, B would activate $X$ 's nodes in the A2 state due to the within-compound association between $\mathrm{B}$ and $\mathrm{X}$ also already formed, the inhibitory properties of which could be responsible of the subjects' performance. But this mechanism is relatively 
implausible when trying to explain our human experiments, because, in our experiments, $\mathrm{X}$ was always presented first, and either A or B was presented second, thus allowing unidirectional within-compound associations only (i.e., $\mathrm{X} \rightarrow \mathrm{A}$ and $\mathrm{X} \rightarrow \mathrm{B}$ ).

However, Dickinson and Burke's (1996) proposal still allows an account of the present human experiments. It implys the formation of excitatory associations between $\mathrm{A}$ and $\mathrm{B}$, while preexposing $\mathrm{AX}$ and $\mathrm{BX}$, instead of inhibitory ones. Perhaps XA and XB are perceived relatively close in time, thus allowing A and B's nodes to be simultaneously activated in the A1 state, with the consequence of excitatory associations being formed. If this is the case, the presence of A in the conditioning trial would activate B's nodes in the A2 state, and this would allow an inhibitory association between $B$ and the outcome of the trial, so that B would become a conditioned inhibitor during the conditioning trial. But there is evidence, both with nonhuman subjects (Espinet et al., 1995, Experiment 1), and with human ones (Graham, 1999, Experiment 1) that this kind of reasoning is not substantiated. Both in the Espinet et al. (1995) study and in the Graham (1999) study, there was a group of subjects for which spaced alternated preexposure to two compound stimuli, $\mathrm{AX}$ and $\mathrm{BX}$, was followed by a conditioning of the common element, $X$. When, subsequently, B was tested either on a retardation test (Espinet et al., 1995) or on a summation test (Graham, 1999), it never acted as a conditioned inhibitor, but, rather, it acted as a conditioned excitor. These results question the explanation of the present summation and retardation effects, based on Dickinson and Burke's theory, related to the formation of excitatory associations between A and B while alternately preexposing $\mathrm{AX}$ and $\mathrm{BX}$.

The results of the present Experiment 4 seem to favor the mechanism proposed by Bennett et al. (1999) mechanism within the McLaren et al. (1989) model. It is the only explanation we know that can satisfactorily explain all the results that we have found. This account allows that an absent, remembered, and expected stimulus can change its associative strength, but, most important, it does not allow that an absent, remembered, but unexpected stimulus could do so. There is now sufficient evidence (Bennett et al., 1999; Graham, 1999; Experiment 4 of the present study) to minimize the mechanism proposed by Espinet et al. (1995). Taken together, these last experiments along with those of mediated excitatory conditioning and reevaluation effects seem to indicate that the associative strength of a stimulus can change in its absence only if the subject expects the stimulus (i.e., only when the stimulus is positively activated). When the absent stimulus is remembered but is not expected (i.e., when the stimulus is negatively activated), the empirical evidence available so far shows that its associative strength does not seem to vary.
If the previous theoretical reasoning is correct, the present study suggests that a stimulus without negative associative strength might be able to pass both summation and retardation tests satisfactorily. A main implication is that our beliefs about how to identify a supposed conditioned inhibitor(Rescorla, 1969; Williams, Overmier, \& Lolordo, 1992) could be in trouble. Obviously, more research is needed to answer this doubt.

\section{REFERENCES}

Arcediano, F., Ortega, N., \& Matute, H. (1996). A behavioural preparation for the study of human Pavlovian conditioning. Quarterly Journal of Experimental Psychology, 49B, 270-283.

Artigas, A. A., \& Chamizo, V. D. (1994). Efectos de la preexposición a un sabor más o menos complejo en la adquisición de una aversión y en la generalización a un segundo sabor [Effects of preexposure to a more or less complex flavor in the acquisition of an aversion and in generalization to a second flavor]. Psicológica, 15, 85-99.

Bennett, C. H., \& Mackintosh, N. J. (1999). Comparison and contrast as a mechanism of perceptual learning? Quarterly Journal of Experimental Psychology, 52B, 253-272.

Bennett, C. H., Scahill, V. L., Griffiths, D. P., \& Mackintosh, N. J. (1999). The role of inhibitory associations in perceptual learning. Animal Learning \& Behavior, 27, 333-345.

Bennett, C. H., Wills, S. J., Wells, J. O., \& Mackintosh, N. J. (1994). Reduced generalization following preexposure: Latent inhibition of common elements or a difference in familiarity? Journal of Experimental Psychology: Animal Behavior Processes, 20, 232239.

Catena, A., Maldonado, A, \& Cándido, A. (1998). The effect of the frequency of judgment and the type of trials on covariation learning. Journal of Experimental Psychology: Human Perception \& Performance, 24, 481-495.

Chamizo, V. D., \& Mackintosh, N. J. (1989). Latent learning and latent inhibition in maze discriminations. Quarterly Journal of Experimental Psychology, 41B, 21-31.

Cleeremans, A. (1997). Sequence learning in a dual-stimulus setting. Psychological Research, 60, 72-86.

Colle, H. A., \& Welsh, A. (1976). Acoustic masking in primary memory. Journal of Verbal Learning \& Verbal Behavior, 15, 17-31.

Dickinson, A. \& BURKe, J. (1996). Within compound associations mediate the retrospective revaluation of causality judgements. Quarterly Journal of Experimental Psychology, 49B, 60-80.

Dwyer, D. M., Mackintosh, N. J., \& Boakes, R. A. (1998). Simultaneous activation of the representations of absent cues results in the formation of excitatory association between them. Journal of Experimental Psychology: Animal Behavior Processes, 24, 163-171.

Espinet, A., Iraola, J. A., Bennett, C. H., \& Mackintosh, N. J. (1995). Inhibitory associations between neutral stimuli in flavoraversion conditioning. Animal Learning \& Behavior, 23, 361-368.

FRENSCH, P. A., \& Miner, C. S. (1994). Effects of presentation rate and individual differences in short-term memory capacity on an indirect measure of serial learning. Memory \& Cognition, 22, 95-110.

GraHAM, S. (1999). Retrospective revaluation and inhibitory associations: Does perceptual learning modulate our perception of the contingencies between events? Quarterly Journal of Experimental Psychology, 52B, 159-185.

Hall, G. (1991). Perceptual and associative learning. Oxford: Clarendon Press.

HALL, G. (1996). Learning about associatively activated stimulus representations: Implications for acquired equivalence and perceptual learning. Animal Learning \& Behavior, 24, 233-255.

Harris, J. A., \& Westbrook, R. F. (1998). Retroactive revaluation of an odor-taste association. Animal Learning \& Behavior, 26, 326-335. 
Holland, P. C. (1981). Acquisition of representation-mediated conditioned food aversions. Learning \& Motivation, 12, 1-8.

Holland, P. C. (1990). Event representation in Pavlovian conditioning. Cognition, 37, 105-131.

Honey, R C., BAteson, P., \& Horn, G. (1994). The role of stimulus comparison in perceptual learning: An investigation with the domestic chick. Quarterly Journal of Experimental Psychology, 47B, 83-103.

JimÉNEZ, L., \& MÉNDEZ, C. (1999). Which attention is needed for implicit sequence learning? Journal of Experimental Psychology: Learning, Memory, \& Cognition, 25, 236-259.

JonEs, D. M. (1993). Objects, streams and threads of auditory attention. In A. D. Baddeley \& L. Weiskrantz (Eds.), Attention: Selection, awareness and control (pp. 87-103). Oxford: Oxford University Press.

Larkin, M. J. W., Aitken, M. R. F., \& Dickinson, A. (1998). Retrospective revaluation of causal judgments under positive and negative contingencies. Journal of Experimental Psychology: Learning, Memory, \& Cognition, 24, 1331-1352.

Leonard, S., \& HALl, G. (1999). Representation-mediated inhibitory learning in the conditioned-suppression procedure. Quarterly Journal of Experimental Psychology, 52B, 145-158.

Mackintosh, N. J., Kaye, H., \& Bennett, C. H. (1991). Perceptual learning in flavour aversion conditioning. Quarterly Journal of Experimental Psychology, 43B, 297-322.

Matute, H., Arcediano, F., \& Miller, R. R. (1996). Test question modulates cue competition between causes and between effects. Journal of Experimental Psychology: Learning, Memory, \& Cognition, 22, 182-196.

McCleland, J. L., \& Rumelhart, D. E. (1985). Distributed memory and the representation of general and specific information. Journal of Experimental Psychology: General, 141, 159-188.

McLaren, I. P. L., Kaye, H., \& Mackintosh, N. J. (1989). An associative theory of the representation of stimuli. In R. G. M. Morris (Ed.), Parallel distributed processing: Implications for psychology and neurobiology (pp. 102-130). Oxford: Oxford University Press.

McLaren, I. P. L., \& Mackintosh, N. J. (2000). An elemental model of associative learning: Latent inhibition and perceptual learning. Animal Learning \& Behavior, 28, 211-246.

Miller, R. R. \& Matute, H. (1996). Biological significance in forward and backward blocking: Resolution of a discrepancy between animal conditioning and human causal judgment. Journal of Experimental Psychology: General, 125, 370-386.

Miller, R. R., \& Matzel, L. D. (1988). The comparator hypothesis: A response rule for the expression of associations. In G. H. Bower (Ed.), The psychology of learning and motivation (Vol. 22, pp. 5192). San Diego: Academic Press.

PerIs, J. M. (1990, June). Sobre un modelo de memoria asociativa [On a model of associative memory]. Paper presented at the 2nd Congress of the Sociedad Española de Psicología Comparada, San Sebastián.

Pineño, O., Ortega, N., \& Matute, H. (2000). The relative activation of the associations modulates interference between elementallytrained cues. Learning \& Motivation, 31, 128-152.

Prados, J., Chamizo, V. D., \& Mackintosh, N. J. (1999). Latent inhibition and perceptual learning in a swimming pool navigation task. Journal of Experimental Psychology: Animal Behavior Processes, 25, 37-44.

Rescorla, R. A. (1969). Conditioned inhibition. Psychological Bulletin, 72, 77-94.

Rescorla, R. A., \& Cunningham, C. L. (1978). Within-compoundfla- vor associations. Journal of Experimental Psychology: Animal Behavior Processes, 2, 267-275.

Rescorla, R. A., \& WAGNer, A. R. (1972). A theory of Pavlovian conditioning: Variations in the effectiveness of reinforcement and nonreinforcement. In A. H. Black \& W. F. Prokasy (Eds.), Classical conditioning II: Current research and theory (pp. 64-99). New York: Appleton-Century-Crofts.

Rizley, R. C., \& Rescorla, R. A. (1972). Associations in second-order conditioning and sensory preconditioning. Journal of Comparative \& Physiological Psychology, 81, 1-11.

Rodrigo, T., Chamizo, V. D., McLaren, I. P. L., \& Mackintosh, N. J. (1994). Effects of preexposure to the same or different pattern of extra-maze cues on subsequent extra-maze discrimination. Quarterly Journal of Experimental Psychology, 47B, 15-26.

Sansa, J., Chamizo, V. D., \& Mackintosh, N. J. (1996). Aprendizaje perceptivo en discriminaciones espaciales [Perceptual learning in spatial discriminations]. Psicológica, 17, 279-295.

Savastano, H. I., Cole, R. P., Barnet, R. C., \& Miller, R. R. (1999). Reconsidering conditioned inhibition. Learning \& Motivation, 30, 101-127.

Schneider, W., \& Shiffrin, R. M. (1997). Controlled and automatic human information processing: I. Detection, search and attention. Psychological Review, 84, 1-66.

SHANKs, D. R. (1985). Forward and backward blocking in human contingency judgment. Quarterly Journal of Experimental Psychology, 37B, $1-21$.

Shanks, D. R., \& Dickinson, A. (1987). Associative accounts of causality judgment. In G. H. Bower (Ed.), The psychology of learning and motivation (Vol. 21, pp. 229-261). San Diego: Academic Press.

Shanks, D. R., \& Dickinson, A. (1991). Instrumental judgment and performance under variations in action-outcome contingency and contiguity. Memory \& Cognition, 19, 353-360.

Shanks, D. R., \& ST. John, M. F. (1994). Characteristics of dissociable human learning systems. Behavioral \& Brain Sciences, 17, 367-447.

StAdLER, M. A. (1995). Role of attention in implicit learning. Journal of Experimental Psychology: Learning, Memory, \& Cognition, 21, 674-685.

Symonds, S., \& HALl, G. (1995). Perceptual learning in flavour aversion conditioning: Roles of stimulus comparison and latent inhibition of common stimulus elements. Learning \& Motivation, 26, 203-219.

Van Hamme, L. J., \& Wasserman, E. A. (1994). Cue competition in causality judgements: The role of non-representation of compound stimulus elements. Learning \& Motivation, 25, 127-151.

WAGNER, A. R. (1981). SOP: A model of automatic memory processing in animal behavior. In N. E. Spear \& R. R. Miller (Eds.), Information processing in animals: Memory mechanisms (pp. 5-47). Hillsdale, $\mathrm{NJ}$ : Erlbaum.

WASSERMAN, E. A. (1993). Comparative cognition: Toward an understanding of cognition in behavior. Psychological Science, 4, 156-161.

Williams, D. A., Overmier, J. B., \& Lolordo, V. M. (1992). A reevaluation of Rescorla's early dictums about Pavlovian conditioned inhibition. Psychological Bulletin, 111, 275-290.

Yin, H., Barnet, R. C., \& Miller, R. R. (1994). Second-order conditioning and Pavlovian conditioned inhibition: Operational similarities and differences. Journal of Experimental Psychology: Animal Behavior Processes, 20, 419-428.

Young, M. E. (1995). On the origin of personal causal theories. Psychonomic Bulletin \& Review, 2, 83-104. 
One implementation of the McLaren et al.'s (1989) model of the representation of stimuli is a system in which there is a certain number of elements or "nodes" (Node 1, Node 2, Node $3, \ldots$ ). At any moment, each node has one "activation," $\Omega_{1}, \Omega_{2}, \Omega_{3}, \ldots$ (which in the present work varied between -1 and +1 ), and is connected with all the remaining nodes of the system. As we can see in Figure A1, the connection from Node 2 to Node 1 has one "weight," $w_{12}$ (where the right subindex refers to the starting node, and the left one refers to the arrival node). Each node can receive external, $e$, and internal, $x$, inputs. The external inputs come from outside the system $\left(e_{1}, e_{2}, e_{3}, \ldots\right)$. We assume that external inputs are positive. The internal inputs come from other nodes, through the connections, and they can take positive or negative values. The internal input from Node 2 to Node 1 will be, $x_{12}=w_{12} \Omega_{2}$. The internal input to Node 1 is the sum of the internal inputs from the remaining nodes,

$$
x_{1}=x_{12}+x_{13}+\cdots=w_{12} \Omega_{2}+w_{13} \Omega_{3}+\cdots .
$$

The total input a node can receive (e.g., Node 1$)$ is the sum of its external and internal inputs $\left(x_{1}+e_{1}\right)$.

The activation of a node depends on the total input it receives and varies according to the following rules: (1) The change in the activation of a node is proportional to the total input it has recently received. To first approximation, $\delta \Omega_{i}=E\left(e_{i}+x_{i}\right)$, where $\delta \Omega_{i}$ is the change in the activation of a node, and $E$ is a constant. When the total input is positive, the activation increases, and when it is negative, it decreases. (2) Additionally, in the absence of any input, the activation tends to change toward zero, at a rate proportional to its current activation (absolute value). (3) There is also a saturation condition that stops the activation from exceeding its limit of \pm 1 . Given some external input and some weights on its connections, a state of equilibriuminside the system is reached, which depends on the external input and on the value of the different weights. For example, for a given total positive input, the activation grows until its rate of increase equals its rate of decrease, in which case the activation stabilizes.

As described, the system is a model to represent stimuli, but not a learning model. To account for learning, the model allows modification of the weights. This is achieved with the delta rule of Widrow and Hoff (e.g., McClelland \& Rumelhart, 1985): The weights change in the sense that, at each node, the internal inputs adjust toward equaling its external input. The formula that allows the weight variation of a connection is $\delta w_{i j}=$ $S \Delta_{i} \Omega_{j}$, where $\delta w_{i j}$ is the change in the associative strength from Node $j$ to Node $i, \Delta_{i}=e_{i}-x_{i}$, and where $S$ is a positive constant. The equilibrium state (i.e., when no more changes occur) is reached when $\Delta_{i}=0$ (i.e., when $x_{i}=e_{i}$ ).

The presentation of one stimulus constitutes external input in to the system directed toward a set of nodes, the representation of the stimulus. The magnitude of the external input will depend on the salience of the stimulus. In the presence of a stimulus, its nodes will be positively activated. For this reason, only positive values of the external input are allowed. Internally activating the nodes assigned to a stimulus (i.e., activating its representation)implies remembering the stimulus. A stimulus can be remembered in two ways: positively (which indicates that the stimulus is expected) and negatively (which indicates that the stimulus is not expected). In the second case, which refers to remembering a specific stimulus that is expected not to occur, this is only possible if the inputs to its nodes are internal and negative. We have to take into account that it is impossible to present the absence of a stimulus, but that it is possible to remember that one specific stimulus is not present (i.e., negative internal input). An activation of a value of zero indicates that the stimulus is not remembered at all.

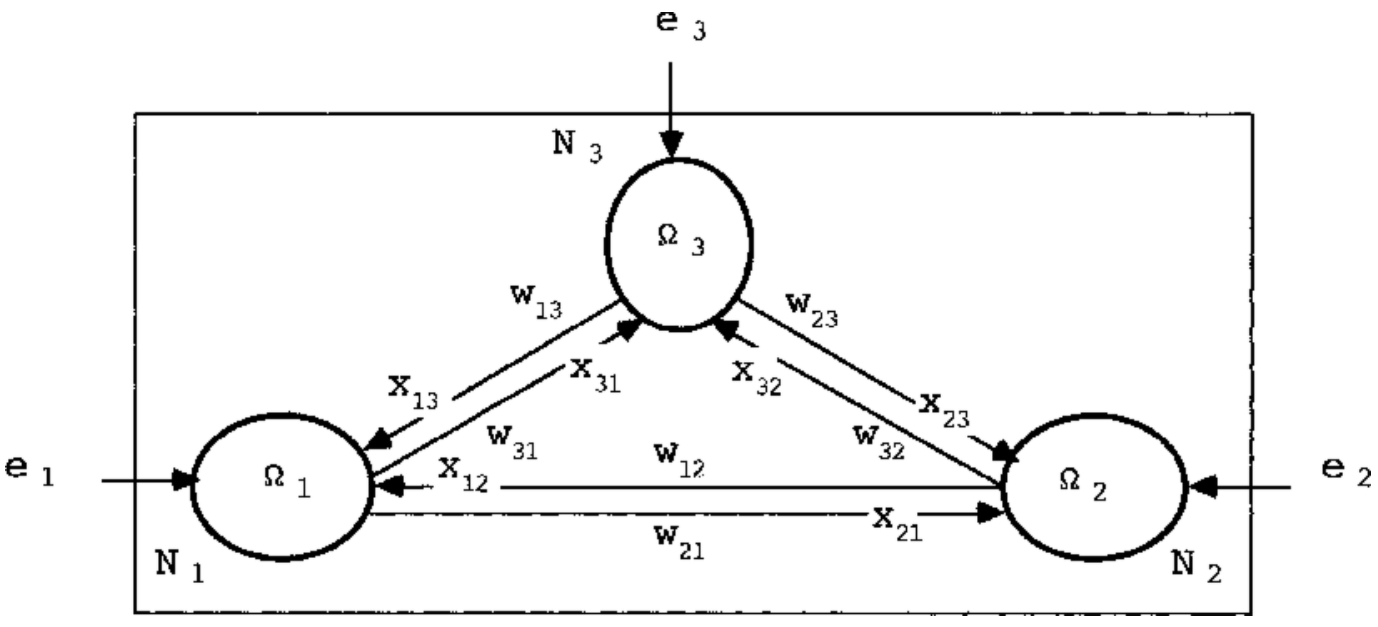

Figure A1. A representation of a set of nodes inside the system, with their external and internal inputs. 


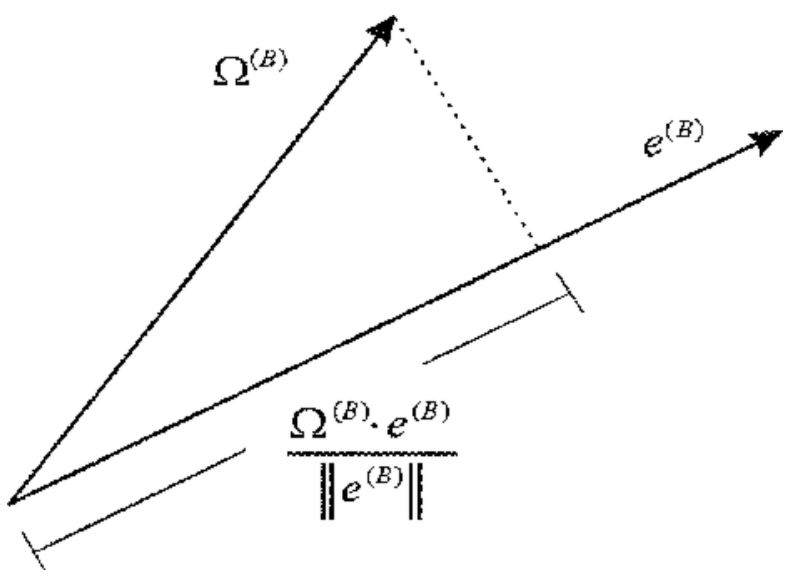

Figure A2. Computation of the total associative strength (TAS) from $A$ to $B$. The TAS from $A$ to $B$ is the fraction, or proportion, of $B$ [the length of vector $e^{(B)}$ that produces the projection of vector $\Omega^{(\mathrm{B})}$ resulting of presenting $\mathrm{A}\left[e^{(\mathrm{A})}\right]$.

The weight between two nodes, Node 1 and Node 2, indicates the amount of association between these nodes. The weight can be positive (excitatory association) or negative (inhibitory association). On the assumption that A and B are two stimuli presented to the system, the weights of the associations between Stimulus A's nodes and Stimulus B's nodes are only a part of the total association between these stimuli. The reason for this is that Stimulus A could be associated with an absent stimulus, Stimulus C, which in turn could be associated with Stimulus B. In other words, normally, the association between two stimuli not only implicates the connection of many nodes but, most importantly, it is also affected by those stimuli that are remembered, without being present when the association occurs. In the present implementation, the association between two stimuli (e.g., from Stimulus A to Stimulus B) was calculated by simulation in which A was present to the system, and we measured the activation it provoked in the nodes that represented Stimulus B.

The above-mentioned processes can be expressed by the following equations. These equations are the ones we have used in the present implementation of the McLaren et al. (1989) model, with which we simulated the present research (see Figure 5 and Figure A3). In all cases, the number of nodes was 24. One single stimulus was represented by a vector of dimension 24 with only six entries that differ from zero. For example, Stimulus A was the vector $e^{(\mathrm{A})}=(0.5,1,0.5,1,0.5,1,0, \ldots, 0)$; Stimulus B was the vector $e^{(\mathrm{B})}=(0,0,0,0,0,0,0.5,1$, $0.5,1,0.5,1,0, \ldots, 0)$; and Compound Stimulus $\mathrm{AB}$ was represented by the vector $e^{(\mathrm{AB})}=(0.5,1,0.5,1,0.5$, $1,0.5,1,0.5,1,0.5,1,0, \ldots, 0)$.

The sequence of calculations used was as follows:

Step 1: All activations and weights were set to zero.

Step 2: One stimulus was presented to the system-that is, the external entries $\left(e_{1}, \cdots, e_{24}\right)$ were set equal to the vector that represented the stimulus;

Step 3: The equations were executed in the following two phases.

(1) The activations are adjusted until they stabilize,

$$
\Omega_{i}^{(k+1)}=\Omega_{i}^{(k)}+E\left(\sum_{j=1}^{j=n} w_{i j} \Omega_{j}^{(k)}+e_{i}\right)\left(1-\left|\Omega_{i}^{(k)}\right|\right)-D \Omega_{i}^{(k)}, i=1 \ldots n .
$$

That is, this calculation is made for $k=1,2, \cdots$ until $\left|\Omega_{i}^{(k+1)}-\Omega_{i}^{(k)}\right|$ was sufficiently small (e.g., $\left.10^{-8}\right)$. Note that the term inside the big parentheses is the total input to Node $i$, that being

$$
x_{i}^{(k)}=\sum_{j=1}^{j=n} w_{i j} \Omega_{j}^{(k)},
$$

the internal input, and $e_{i}$ the external input. $D$ is a decay constant.

(2) The weights are adjusted only once,

$$
w_{i j}{ }^{\text {(new) }}=w_{i j}{ }^{\text {(former) }}+S\left(e_{i}-x_{i}\right) \Omega_{j}, \quad i, j=1 \cdots n, \quad i \neq j, w_{i i}=0 .
$$

This completes one simulated presentation of one stimulus. A new presentation begins in Step 2.

When a real experiment is to be simulated, a certain number of simulated presentations has to be assigned to each real unit of time. For example, a preexposure of Stimulus A for $20 \mathrm{~min}$ could be equivalent to 20 presentations of the simulated stimulus, at the rate of one presentation every minute.

We have used the simplest implementation of the McLaren et al.'s (1989) model, which has been obtained (1) by setting to zero the other parameters of the model's equations (which are irrelevantin the present simulations) 


\section{APPENDIX A (Continued)}

and (2) by discretizing in one of the many possible ways the differentialequationsin order to convert them into difference equations. This last manipulation has no effect on the qualitative evolution of the system in the simulations of the present study (in Figure 5 and Figure A3), provided a reasonable tuning of parameters has been made.

For example, let's suppose that Stimulus A and Stimulus B are associated. How can the amount of association from A to B be measured? In order to do this, Stimulus A and only A is presented once, until the activations are stabilized. The presentation of A activates B's nodes. The activation in B's nodes is the vector $\Omega$ (B), whereas Stimulus B is represented by the vector $e^{(\mathrm{B})}$ (both vectors, $\Omega^{(\mathrm{B})}$ and $e^{(\mathrm{B})}$, occupy positions 7-12). Figure A2 refers to this example.

The total associative strength (TAS) from A to B is computed with the equation,

$$
\operatorname{TAS}_{\mathrm{A} \rightarrow \mathrm{B}}=\frac{\Omega^{(\mathrm{B})} \times e^{(\mathrm{B})}}{\left\|e^{(\mathrm{B})}\right\|} /\left\|e^{(\mathrm{B})}\right\|,
$$

which, expressed in components, is as follows:

$$
\operatorname{TAS}_{\mathrm{A} \rightarrow \mathrm{B}}=\left(\sum_{i=7}^{i=12} \Omega_{i}^{(\mathrm{B})} e_{i}^{(\mathrm{B})}\right) /\left(\sum_{i=7}^{i=12}\left(e_{i}^{(\mathrm{B})}\right)^{2}\right) .
$$

As can be seen in Figure A2, the numerator of the first of the above formula is the norm (or modulus) of the projection of the activations of vector $\Omega^{(\mathrm{B})}$ over vector $e^{(\mathrm{B})}$, and $\left\|e^{(\mathrm{B})}\right\|$ is the modulus of vector $e^{(\mathrm{B})}$.

In order to present additional examples of how to measure the amount of association from $\mathrm{A}$ to $\mathrm{B}$, let us suppose a vector $\Omega^{(\mathrm{B})}$ of fixed length situated in different directions. If vector $\Omega$ (B) is on vector $e^{(\mathrm{B})}$ and in the same sense, then the $\operatorname{TAS}_{A \rightarrow B}$ value is maximum. But when vector $\Omega(B)$ is in a perpendicular direction to vector $e^{(\mathrm{B})}$, its projection (and therefore the $\mathrm{TAS}_{\mathrm{A} \rightarrow \mathrm{B}}$ ) is zero: The system does not reproduce Stimulus B. Finally, let us suppose that vector $\Omega^{(\mathrm{B})}$ has some negative activations. Because all the external inputs of vector $e^{(\mathrm{B})}$ are positives, vector $\Omega^{(\mathrm{B})}$ will form an angle of more than $90^{\circ}$ with vector $e^{(\mathrm{B})}$, and the $\mathrm{TAS}_{\mathrm{A} \rightarrow \mathrm{B}}$ will be negative. On the other hand, as can be seen in Figure A2, the longer the length of vector $\Omega^{(B)}$, the bigger the $\operatorname{TAS}_{A \rightarrow B}$ will be. Here ends the description of the implementation of the model that we have used.

To adjust the parameters $E, D$, and $S$ of the model and also the number of simulated presentations that correspond to a unit of real time, we planned a simulation of simple conditioning and adjusted the parameters until the result was satisfactory. Then, with the same parameters, we simulated some basic Pavlovian phenomena (specifically, blocking and overshadowing). Again with the same parameters, we carried out all the simulations that are presented in this paper. We consider that this is important because a system of equations with many parameters adjusted ad hoc could simulate practically anything (Peris, 1990).

We now describe the mechanism by which the inhibitory associations are formed. For simplicity, Stimuli A, B, ... are represented in the Nodes A, B, ..., respectively. An inhibitory association from A to B will be formed if, after the presentation of A, a subject expects B, but B does not physically appear. Suppose that Stimuli AX, BX, AX, BX, and so on, are presented. When $\mathrm{AX}$ is first presented, $\mathrm{A} \rightarrow \mathrm{X}$ and $\mathrm{X} \rightarrow \mathrm{A}$ associations are formed. In terms of the model, $\mathrm{A}$ and $\mathrm{X}$ each receives an external input, let's say $e_{\mathrm{A}}=1 ; e_{x}=1$. Therefore, $\Delta_{\mathrm{A}}=e_{\mathrm{A}}>0, \Omega>0$, and $\delta w_{\mathrm{AX}}=\Omega_{\mathrm{X}} \Delta_{\mathrm{A}}$. A positive weight will be formed from X to A. In the same way, $\Delta_{\mathrm{X}}=$ $e_{x}>0, \Omega_{\mathrm{A}}>0$, and $\delta w_{\mathrm{XA}}=\Omega_{\mathrm{A}} \Delta_{\mathrm{X}}>0$. A positive weight will be formed from A to X. That is, mutually excitatory associations $\mathrm{A} \rightarrow \mathrm{X}$ and $\mathrm{A} \rightarrow \mathrm{X}$ are formed. Then, when $\mathrm{BX}$ is presented, $\mathrm{A}$ receives a positive internal input from $X$ (because $X$ is externally excited and the weight from $X$ to $A$ is positive) and its external input is zero (A is not physically present), whereas B is externally excited.

Thus, A is a remembered and expected stimulus that is not physically present; and, therefore, a negative weight will be established from $\mathrm{B}$ to $\mathrm{A}, \mathrm{a} \mathrm{B} \dashv \mathrm{A}$ association. In terms of the model, this means that $\mathrm{B}$ receives an external input, let's say $e_{\mathrm{B}}=1$, and that A receives an internal and positive input, $x_{\mathrm{A}}>0$ ( $\mathrm{A}$ is remembered and expected), but an external input of zero, $e_{\mathrm{A}}=0$ (A is not physically present). Therefore, $\Delta_{\mathrm{A}}=e_{\mathrm{A}}-x_{\mathrm{A}}=$ $0-x_{\mathrm{A}}<0, \Omega_{\mathrm{B}}>0$, and $\delta w_{\mathrm{AB}}=\Omega_{\mathrm{B}} \Delta_{\mathrm{A}}<0$. A negative weight will be formed from B to A-that is, an inhibitory association $\mathrm{B} \dashv \mathrm{A}$. It is important to emphasize that a previous $\mathrm{A} \rightarrow \mathrm{X}$ association is necessary for a $\mathrm{B} \dashv \mathrm{A}$ association to be formed and that the equilibrium state for the $\mathrm{B} \dashv \mathrm{A}$ weight (i.e., when $\Delta_{\mathrm{A}}=0$ ) is reached when $x_{\mathrm{AB}}$ (from $\mathrm{B}$ to $\mathrm{A}$ ) is equal and opposite in sign to positive $x_{\mathrm{AX}}$ (from $\mathrm{X}$ to $\mathrm{A}$ ). Then, when Stimulus AX is presented for the second time, due to the association $\mathrm{X} \rightarrow \mathrm{B}$ previously formed during the presentation of $\mathrm{BX}$, the $\mathrm{A} \dashv \mathrm{B}$ association will be augmented. The weights of these associations will grow as the compound stimuli, $\mathrm{AX}$ and $\mathrm{BX}$, are presented in this alternate pattern. The associative strength from $\mathrm{A}$ to $\mathrm{B}$ arises from $\mathrm{A} \rightarrow \mathrm{X} \rightarrow \mathrm{B}$ (positive weights $w_{\mathrm{XA}}$ and $w_{\mathrm{BX}}$ ) and $\mathrm{A} \dashv \mathrm{B}$ (negative weight $w_{\mathrm{BA}}$ ).

Figure A3 illustrates the relation between the net associative strength between A and B (denoted A $\leftrightarrow B$ because of the symmetry of $\mathrm{A}$ and $\mathrm{B}$ ) and the amount of pretraining exposure alternately to AX and BX. The top dashed curve shows the evolution of weights between $A$ and $X$ and between $B$ and X, which positively increases until an asymptotic level is reached. The bottom dashed curve shows the evolution of inhibitory weight between A and B over preexposure trials, which negatively increases until an asymptotic level is reached. The middle curve (solid line) shows the net associative strength between A and B, which is initially excitatory and, as preexposure progresses, gradually becomes inhibitory. 


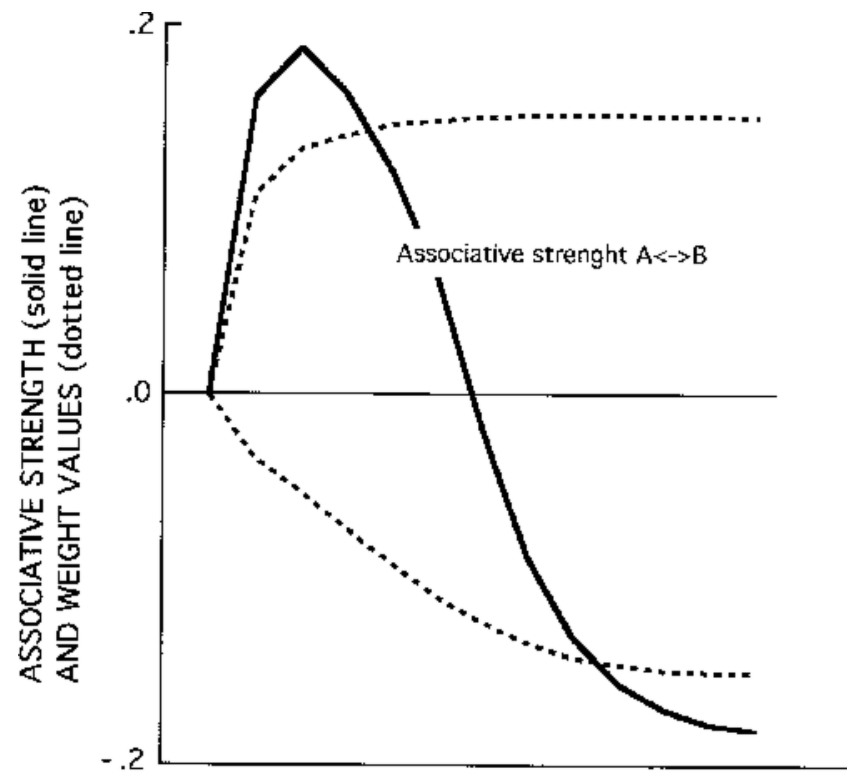

AMOUNT OF PREEXPOSURE

Figure A3. Simulation of alternating preexposure to two compound stimuli ( $A X$ and $B X)$ containing a common element $(X)$. The middle curve (solid line) shows the associative strength between $\mathrm{A}$ and $B$. The top curve denotes the weights evolution between $A$ and $X$ and between $B$ and $X$. The bottom curve denotes the reciprocal weights evolution between $A$ and $B$ (see text for explanation).

\section{APPENDIX B}

\section{Instructions for Days 1 and 2 of Experiment 4}

This session will last approximately $20 \mathrm{~min}$. It will consist of the presentation of some sequences of sounds which you will hear through the pair of headphones you have on your left. The only thing you have to do is to get familiar with the sequences of sounds. Please pay a lot of attention to them!

\section{Instructions for Day 3 of Experiment 4}

This session will last approximately $20-25 \mathrm{~min}$. It will have three phases in which you will be presented, through the headphones, with some sequences of sounds separated by brief intervals of silence. At the beginning of each phase you will have a reminder of its content.

Phase 1 is very brief. As on previous days, the only thing you have to do is to get familiar with the sequences of sounds. Please pay a lot of attention to them.

Phase 2 is like a game. You will have to guess which of two composers, Composer Black or Composer Red, produced each "melody." The red and the green lights simultaneously illuminated will indicate the right moment for you to give a response after hearing a sequence of sounds. You will begin by guessing. For example, pressing the black button of the little box you have in front of you for Composer Black, or the red button for Composer Red. If your choice is correct, the green light will appear for a brief moment, and if it is incorrect, the red light will be illuminated. It is important that you behave spontaneously. We are interested in your first impression. It is also important that you always give a response.
Phase 3 is another game, very similar to Phase 2 except that we will not tell you whether your choices are right or wrong.

(Let's see a couple of examples of Phase 2 before we begin with the real session...)

\section{Reminder of Phase 1}

Remember that during Phase 1 the only thing you have to do is to pay a lot of attention to the sequences of sounds with which you will be presented. Please, put your headphones on. Are you ready? OK, Phase 1 starts!

\section{Reminder of Phase 2}

Now you have to guess which of the two composers, Black or Red produced each "melody." To do so, you will have to press either the black or the red button. Remember that if your choice is correct, the green light will be illuminated, and if it is incorrect, the red light will appear. Please, put your headphones on. Are you ready? OK, Phase 2 starts!

\section{Reminder of Phase 3}

Phase 3 is like Phase 2 except that we will not tell you whether your choices are right or wrong. Please, put your headphones on. Are you ready? OK, Phase 3 starts! revision accepted for publication June 12, 2000.) 